\title{
Produtividade do Trabalho e Economias de Aglomeração: Evidências para o Estado da Bahia
}

\author{
Kecia Cristina Miranda da Silva ${ }^{1}$ | José Firmino Sousa Filho ${ }^{2}$ (D) | Fernanda Oliveira Caires e \\ Caires $^{3}$ | Diana Lúcia Gonzaga da Silva ${ }^{4}$ \\ ${ }^{1}$ Universidade Federal da Bahia. E-mail: keciamiranda@gmail.com \\ ${ }^{2}$ Universidade Federal da Bahia. E-mail: firminofilho93@gmail.com \\ ${ }^{3}$ Universidade Federal da Bahia. E-mail: fernanda.o.caires@hotmail.com \\ ${ }^{4}$ Universidade Federal da Bahia. E-mail: dlgsilva@ufba.br
}

\begin{abstract}
RESUMO
Este artigo analisa o efeito das economias de aglomeração sobre a produtividade do trabalho no estado da Bahia no período de 2002 a 2016. A literatura aponta que a produtividade do trabalho depende da estrutura produtiva local e das externalidades de aglomeração. Utilizou-se um modelo de dados em painel dinâmico para estimar indicadores da produtividade do trabalho em nível municipal. O Método dos Momentos Generalizados - GMM System - com variáveis instrumentais foi adotado para lidar com a produtividade defasada e os fatores não observados dos municípios. A análise foi feita em duas etapas considerando os municípios fora do Semiárido (Grupo 1) e o conjunto de municípios do Semiárido (Grupo 2). Os resultados mostraram que a produtividade do trabalho defasada exerceu maior influência sobre os niveis de produtividade atuais, principalmente para o Grupo 1. Para ambos os grupos, os coeficientes de especialização (QL) e diversificação setorial (HHM) apresentaram efeito negativo na maioria dos setores analisados. Não foram encontradas evidências de externalidades positivas de aglomeração, a partir do tamanho populacional e das densidades da população e do emprego. As demais variáveis socioeconômicas apresentaram resultados distintos entre os grupos analisados.
\end{abstract}

\section{PALAVRAS-CHAVE}

dutividade do trabalho, Bahia, Economias de aglomeração, Especialização setorial, Diversificação setorial

\section{Labor Productivity and Agglomeration Economies: Evidence for the State of Bahia}

\begin{abstract}
This paper analyzes the effect of agglomeration economies on labor productivity in the State of Bahia from 2002 to 2016. The literature points out that labor productivity depends on the local productive structure and the agglomeration externalities. A dynamic panel data model was used to estimate the indicators of labor productivity at the municipal level. The Generalized Moments Method - GMM System - with instrumental variables was adopted to deal with lagged productivity and unobserved factors in the municipalities. The analysis was carried out in two stages considering the municipalities outside the Semi-Arid (Group 1) and the set of municipalities in the Semi-Arid (Group 2). The results showed that lagged labor productivity had the greatest influence on current productivity levels, especially for Group 1. For both groups, the specialization (QL) and sectoral diversification (HHM) coefficients showed a negative effect in most analyzed sectors. There was no evidence of positive externalities of agglomeration, based on population size and population and employment densities. The other socioeconomic variables showed different results between the groups analyzed.
\end{abstract}

\section{KEYWORDS}

Labor productivity, Bahia, Agglomeration Economies, Sector specialization, Sector Diversification

\section{CLASSIFICAÇÃO JEL}

J24, J21, R10, R12 


\section{Introdução}

A análise de indicadores da produtividade do trabalho é um objeto de estudo na economia que se aprimorou ao longo do tempo, através de teorias e métodos aplicados de forma cada vez mais robusta e rigorosa (Rice et al., 2006; Choudhry, 2009; Squeff e De Negri, 2014). O crescimento da produtividade do trabalho pode se dar através de incrementos de fatores de capital, tais como máquinas e equipamentos de alto padrão tecnológico, na especialização e na qualificação do capital humano, pelos ganhos educacionais e pela formação de habilidades (Marchante e Ortega, 2012; Battisti et al., 2018). Movimentos da demanda agregada que impulsionam os investimentos públicos ou privados também podem influenciar na produtividade do trabalho, assim como o progresso técnico (Gambetti e Pistoresi, 2004).

Outros fatores, como a composição ou a alocação setorial do trabalho, pela mudança estrutural da produção, interferem na produtividade (Krüger, 2008). De modo geral, a presença de aglomerados produtivos pode contribuir para a elevação da produção. Isso ocorre porque a proximidade entre as empresas proporciona spillovers de conhecimento. Ademais, a concentração de mão de obra qualificada de serviços especializados e uma infraestrutura com elementos que sejam capazes de conduzir a uma maior eficiência das atividades impactam positivamente na produtividade (Jacobs, 1970; Raiher e Candido, 2018).

Desse modo, diversos elementos podem explicar as diferenças de produtividade entre distintas regiões. Ciccone e Hall (1996) identificaram que as externalidades geográficas locais e a diversidade de serviços intermediários locais possuíam efeitos sobre as grandes diferenças de produtividade entre as regiões dos EUA. Os resultados indicaram efeito da densidade de empregos sobre a produtividade estadual e sobre a produtividade média do trabalho. Assim, a variação da produção por trabalhador entre os estados foi explicada pelas diferenças na densidade da atividade econômica.

Em estudos realizados para a economia brasileira, Squeff e De Negri (2013); Cavalcante e De Negri (2014) e Messa (2015) afirmam que a indústria de transformação, apesar da constante perda de participação no PIB, continua sendo um setor chave para os incrementos na produtividade total dos fatores e, consequentemente, para a produtividade do trabalho. As pesquisas convergem no sentido do diagnóstico do baixo crescimento ou da estagnação da produtividade da indústria, além de ciclos de crescimento econômicos incapazes de apresentar uma tendência sustentável da produtividade.

A nivel regional, Raiher e Candido (2018) realizaram uma análise espacial a fim de avaliar os efeitos de economias de aglomeração sobre a produtividade industrial dos municípios da região Sul do Brasil. Dentre as principais conclusões da pesquisa, destacou-se que, dada a fraca estrutura tecnológica da indústria brasileira, a especialização produtiva não acarretou diretamente ganhos de produtividade para a região Sul. Raiher (2020) destaca que para as regiões Norte, Nordeste e Centro-Oeste os 
municípios que apresentam maiores padrões de urbanização possuem efeitos de economias de aglomeração sobre a produtividade de forma mais intensa.

A implementação de políticas regionais de incremento na produtividade setorial, seja através de ganhos de capital, seja através do trabalho ou da tecnologia, é essencial para o crescimento sustentado no longo prazo. Portanto, esta pesquisa é motivada pelo questionamento: quais os efeitos das economias de aglomeração sobre a produtividade do trabalho na Bahia entre os anos de 2002 e 2016? A escolha pelo período de análise se deu em função da disponibilidade e da compatibilidade entre as diferentes bases de dados utilizadas na pesquisa. ${ }^{1}$ Além disso, o período é marcado pelo crescimento do PIB brasileiro com o "boom das commodities", a geração de empregos formais, a maior distribuição de renda e o crescimento real do salário mínimo (Hoffmann, 2007; Sacchet e Calixtre, 2011; Komatsu e Menezes-Filho, 2015; Spilimbergo e Srinivasan, 2019). No entanto, o ano de 2012 marca o fim do crescimento impulsionado pela demanda e, consequentemente, inicia-se um ciclo de fraco desempenho da economia brasileira impactando os estados e, em particular, a economia do estado da Bahia (Sousa Filho et al., 2020; SEI, 2020). Esses fatores demarcam um período importante na história recente da economia brasileira, da retomada do crescimento aos novos ciclos de recessão.

A Bahia é um estado com características econômicas e sociais divergentes. Apesar de oscilar entre o $6^{\circ}$ e $7^{\circ}$ estado com o maior PIB do país e se destacar na produção agrícola, de serviços, comércio, turismo e na produção industrial nas áreas químicas e petroquímicas, etc., mantém uma economia altamente concentrada nas suas duas regiões metropolitanas (Região Metropolitana de Salvador-RMS e Região Metropolitana de Feira de Santana-RMFS). Somados, os territórios de identidade das respectivas regiões metropolitanas representaram aproximadamente $50 \%$ de todo o PIB do estado, sendo que apenas o município de Salvador representa de 23,6\% do PIB (SEI, 2015).

Para mensurar a produtividade do trabalho no estado da Bahia, foi utilizado o valor adicionado bruto da produção municipal, a preços constantes de 2016, dividido pelo número de trabalhadores formais dos municípios. O estudo utiliza um modelo de dados em painel dinâmico para estimar os efeitos de indicadores socioeconômicos e economias de aglomeração sobre a produtividade, através do método GMM System. As estimações foram divididas em dois grupos: a região do Semiárido, com 266 municípios (SUDENE, 2007), e os demais 151 municípios fora do Semiárido. A estimação para o grupo de municípios do Semiárido busca entender se a produtividade do trabalho apresenta um comportamento diferente considerando a dinâmica produtiva diferenciada da região.

Nesse sentido, tomando como base as evidências da literatura de economia espacial, o objetivo deste artigo é verificar de que maneira as externalidades positivas de aglomerações afetam a produtividade do fator trabalho. É importante destacar que a

\footnotetext{
${ }^{1}$ Dados relativos à serie atual do valor adicionado bruto por município e do consumo elétrico do comércio e da indústria estavam disponíveis até o ano de 2016.
} 
análise aqui apresentada leva em consideração apenas o emprego formal, o que gera limitações para a pesquisa, dada a alta informalidade do estado da Bahia. No entanto, a restrição é baseada na disponibilidade de dados em nível municipal e com periodicidade anual que permite a estimação de um painel dinâmico para a produtividade do trabalho, de acordo com a literatura. Assim, parte-se do pressuposto de que as cidades que apresentam mercados de trabalho mais amplos concentram uma maior diversidade de trabalhadores qualificados e isso aumenta a produtividade média local. Essa concentração seria uma consequência da escolha de indivíduos e de empresas por melhores salários e maiores lucros, respectivamente, decorrentes dos ganhos de aglomeração no mercado de trabalho.

Para Klein e Crafts (2020), o problema pode ser definido a partir da hipótese de que a estrutura produtiva inicial de uma cidade possui impacto sobre o comportamento da sua produtividade subsequente. Portanto, se os choques de mudanças produtivas e tecnológicas estiverem associados à composição produtiva local, é possivel que as firmas possam prever os seus efeitos e antecipar as suas decisões de localização, o que geraria um problema de endogeneidade potencial entre a estrutura produtiva inicial e as medidas de externalidades de localização e de urbanização.

Assim, o método GMM System permite estimar modelos de dados em painel dinâmicos (persistência temporal) e lidar com o problema de endogeneidade da escolha de insumos na produção, usando defasagens (lags) das variáveis endógenas e exógenas diferenciadas como variáveis instrumentais para a equação em nivel. Dessa forma, é possivel corrigir o problema de instrumento fraco do GMM em primeira diferença, já que o uso da variável defasada como instrumento para a diferença pode apresentar uma correlação muito baixa com a variável endógena diferenciada se houver uma persistência temporal muito alta associada a ela (Van Beveren, 2012).

Os resultados encontrados sugerem que as mudanças na produtividade passada estão associadas com um crescimento de 0,34\%-0,49\% na produtividade corrente para os municípios fora do Semiárido (Grupo 1). Para os municípios do Semiárido (Grupo 2), houve decréscimo e perda de significância estatística das estimativas do efeito da produtividade do trabalho defasada temporalmente, ao serem incluídas variáveis de controle adicionais. Para ambos os grupos, os indicadores de especialização (QL) e diversificação setorial (HHM) apresentaram efeito negativo na maioria dos setores analisados. A educação não se mostrou relevante para explicar as diferenças de produtividade do trabalho entre os municípios. Foi possivel identificar efeitos negativos associados às parcelas de empresas médias e grandes (relativamente às pequenas) e à proporção de beneficiários do Programa Bolsa Família. A parcela de empregos públicos apresentou um efeito positivo apenas para os municípios fora do Semiárido e em uma das especificações estimadas. As medidas de aglomeração associadas ao tamanho da população não apresentaram evidências de externalidades positivas nos dois grupos considerados. No grupo fora do Semiárido, os municípios entre 50 e 100 mil habitantes, apresentaram um efeito negativo sobre a produtividade do trabalho. 
Por sua vez, a densidade do emprego possui um efeito negativo sobre a produtividade do trabalho para ambos os grupos.

Além desta introdução, a pesquisa divide-se em mais quatro seções. A seção 2 é destinada a uma revisão de literatura sobre conceitos clássicos e trabalhos mais recentes sobre efeitos das aglomerações sobre a produtividade. A seção 3 apresenta o banco de dados e os procedimentos metodológicos. A seção 4 mostra os resultados e as discussões sobre as variáveis que podem ser indicadores da produtividade do trabalho nos municípios do estado da Bahia. Por fim, a seção 5 apresenta as considerações finais do estudo.

\section{Efeitos das economias de aglomeração sobre a produtivi- dade e o crescimento}

Economias de aglomeração geralmente são derivadas de dois fatores: (i) da localização ou especialização, que é resultado da concentração de atividades semelhantes no mesmo espaço, (ii) da urbanização ou diversificação, que atrai e mantém firmas pertencentes a segmentos diferentes (Raiher, 2020). Dessa forma, os setores industriais se beneficiam de modos distintos das economias de localização/especialização ou urbanização/diversificação. Isso explica o fato de as empresas manufatureiras obterem mais vantagens quando optam por se localizarem nas regiões metropolitanas em detrimentos de outros centros (Nakamura, 1985). Enquanto a especialização industrial promove os fatores intraindustriais que aumentam a produtividade (externalidades de Marshall), a diversificação pode proporcionar o aumento da produtividade a partir da interação entre indústrias (externalidades de Jacobs) (Klein e Crafts, 2020).

Esses elementos contribuem para o aumento de escala da produção e, consequentemente, elevam o nível de produtividade dos fatores. Neste sentido, Marshall (1890) aponta três elementos de externalidades: a concentração de trabalhadores qualificados, a centralização de serviços e os spillovers de tecnologia. Tais fatores também foram abordados na corrente clássica de desenvolvimento regional, como em Hirschman (1958), em que o desenvolvimento da economia está relacionado à sua estrutura produtiva, à geração de tecnologia e à constituição de mercados consumidores. Sob esse aspecto, o autor ressalta a relevância dos investimentos, em particular, os investimentos públicos. Assim, os três principais padrões de alocação de investimento poderiam ser distinguidos pela dispersão, concentração em áreas já propícias ao crescimento e tentativa de formação de áreas de desenvolvimento em regiões atrasadas economicamente.

O conjunto desses fatores pode definir a decisão por localização das empresas e gerar aglomerações populacionais expressivas em uma região. Segundo Henderson (2003), isso é relevante, pois determina o acesso das empresas às fontes de transbordamentos de informações locais. Dessa forma, empresas intensivas em tecnologia se beneficiam desses transbordamentos em comparação a empresas pouco intensivas 
em tecnologia, como as indústrias de maquinário, por exemplo. Além disso, empresas que dependem do ambiente externo tendem a obter e a gerar menos benefícios, pois os eventos externos podem alterar suas decisões e resultados, conforme ocorre com as empresas de plantas corporativas.

Ciccone e Hall (1996) estudaram os efeitos das aglomerações, baseadas na densidade do emprego, nos estados norte-americanos e encontraram efeitos diversos sobre a produtividade do trabalho. No entanto, os autores afirmam que a densidade do emprego possui um efeito significativo sobre a produtividade nos estados e esse é um fator de crescimento relevante do produto por trabalhador (usada como proxy para a produtividade do trabalho). Em estudo também aplicado à economia dos EUA, Glaeser e Resseger (2010) afirmam que a produtividade do trabalhador está associada às economias de aglomeração. Deste modo, cidades que agregam um maior número de pessoas com mais habilidades tendem a ter um melhor desempenho produtivo. Por outro lado, cidades em que os trabalhadores são pouco habilidosos não se beneficiam dos efeitos das aglomerações e, consequentemente, a produtividade fica comprometida.

Klein e Crafts (2020) examinaram o papel das externalidades dinâmicas de aglomeração para o crescimento da produtividade do trabalho na indústria das cidades dos Estados Unidos, usando um painel para o período de 1880-1930. O estudo encontrou um efeito positivo para a especialização e negativo para a diversificação, fornecendo evidências favoráveis à hipótese da existência das economias de localização marshallianas. No entanto, em algumas cidades muito grandes e com um nivel de diversidade substancial, o efeito da diversificação tornou-se positivo.

Nesse sentido, a densidade urbana funcionaria como elemento propulsor do conhecimento e, por conseguinte, da produtividade. Isto ajuda a explicar por que cidades maiores costumam ter maiores índices de produtividade do trabalho, particularmente nos países desenvolvidos. Porém, dadas as peculiaridades dos países em desenvolvimento e das suas regiões menos desenvolvidas, esses efeitos podem não ser observados. Isso foi evidenciado por (Raiher, 2020) para o caso do Nordeste brasileiro. Ao utilizar uma análise espacial para verificar o efeito de setores industriais e de serviços intensivos em conhecimento no crescimento do econômico do Brasil, a autora observou que a aglomeração no setor industrial se mostrou importante para o aumento no dinamismo econômico dos municípios, entretanto o mesmo não foi verificado para o setor de serviços. O estudo encontrou um efeito negativo para a densidade demográfica, tanto para o Brasil como para as regiões, variando entre $-0,56 \%$ e $-0,82 \%$, e sugeriu que o resultado pode indicar a existência de deseconomias de aglomerações relacionadas ao menor ritmo de crescimento econômico associado a maiores níveis de concentração populacional.

Por sua vez, Moura et al. (2020) encontraram um efeito positivo da densidade demográfica $(0,04 \%)$ sobre o crescimento do PIB per capita dos municípios do estado de Alagoas, no período entre 2000 e 2015, usando um painel dinâmico e o estima- 
dor de GMM System. Os autores explicam que, de acordo com os estudos da Nova Geografia Econômica (NGE), o tamanho populacional pode impactar o desempenho de uma região como uma força centrífuga ou centrípeta. Como força centrífuga, a maior concentração populacional deve afetar negativamente o crescimento econômico e desestimular os investimentos privados, já que esse nível de aglomeração pode gerar maior pobreza, poluição e criminalidade. Por outro lado, como força centrípeta, a maior densidade populacional deve gerar estímulos à instalação de novas indústrias, entre outros fatores, devido ao excesso de mão de obra barata, o que tende a gerar efeitos multiplicadores positivos sobre o crescimento econômico (emprego, renda e consumo).

No entanto, de maneira geral, na região Nordeste as aglomerações não se mostraram relevantes para esse crescimento. Dentre as possiveis razões, destacam-se a fraca estrutura produtiva da região e as lentas taxas de crescimento (Perobelli e Haddad, 2006). de Almeida et al. (2017) também analisaram os efeitos das economias de aglomeração e especialização no Nordeste brasileiro. Os autores observaram que o crescimento das indústrias intensivas em tecnologia se relaciona à maneira como as estruturas são especializadas localmente. Assim, essas estruturas determinam as economias externas e, por consequência, os rendimentos oriundos da especialização.

Isso é importante, pois pode determinar a maneira pela qual ocorre o crescimento da produtividade entre as regiões. Anderle et al. (2018) afirmam que o crescimento da produtividade de determinado municipio afeta positivamente os municípios vizinhos. De acordo com os autores, isso seria resultado da dependência espacial entre as regiões que se beneficiam, mutuamente, do crescimento dos vizinhos e, ao mesmo tempo, concorrem por fatores de produção. Deste modo, a maneira como se estabelece a dinâmica de desenvolvimento local está intrinsecamente relacionada às vantagens que podem ser obtidas pelas firmas. O efeito espraiamento, dependência espacial, transbordamento de vantagens e informações, além dos incentivos financeiros, são elementos que determinam as decisões das empresas por localização. Ademais, a maneira como as regiões se integram e a logística e infraestrutura existentes são fatores que viabilizam o desenvolvimento das regiões e daquelas no seu entorno.

\section{Metodologia e Dados}

Nesta seção, são apresentados os dados utilizados para o desenvolvimento da pesquisa e a metodologia adotada. Para entender se os indicadores da produtividade do trabalho possuem um comportamento diferente entre os municípios que possuem menores dinamismo e renda, realizaram-se uma análise para os municípios da região do Semiárido (266 municípios) e outra para os municípios fora do Semiárido (151 municípios).

As variáveis incluídas no modelo foram baseadas na literatura sobre indicadores da produtividade. O Quadro 1 apresenta a definição das variáveis do modelo e suas 
fontes.

A RAIS é a principal fonte para os dados de empregos formais neste estudo. Todavia, a base não possui informações sobre empregos informais, característica marcante do estado da Bahia. Segundo o IBGE (2018), cerca de 56,7\% da população ocupada na Bahia exercia uma atividade informal. A restrição da análise é explicada pela inexistência de dados em nível municipal com periodicidade anual para o mercado de trabalho informal que permitissem a construção do painel dinâmico para a estimação do modelo econométrico de produtividade do trabalho. Nesse sentido, é importante ressaltar que as conclusões geradas com base nos resultados encontrados não podem ser generalizadas para todo o mercado de trabalho, mas apenas para o segmento formal.

Guadro 1. Variáveis utilizadas na pesquisa: 2002 a 2016

\begin{tabular}{|c|c|c|c|}
\hline Variável & Definição & Fonte & Literatura relacionada \\
\hline Produtividade do trabalho & $\begin{array}{l}\text { VAB a preços constantes dividido } \\
\text { pela população formal ocupada }\end{array}$ & IBGE/RAIS & $\begin{array}{c}\text { Squeff e De Negri (2014) } \\
\text { Cavalcante e De Negri (2014) }\end{array}$ \\
\hline $\begin{array}{l}\text { Percentual de firmas } \\
\text { médias e grandes }\end{array}$ & $\begin{array}{l}\text { Firmas médias são aquelas que } \\
\text { possuem de } 20 \text { a } 100 \text { trabalhadores e } \\
\text { firmas grandes aquelas com mais de } \\
100 \text { trabalhadores }\end{array}$ & RAIS & $\begin{array}{l}\text { Cavalcante e De Negri (2014) } \\
\text { Combes et al. (2012) }\end{array}$ \\
\hline Escolaridade & $\begin{array}{l}\text { Parcela de trabalhadores formais } \\
\text { com ensino fundamental, médio e } \\
\text { superior completos }\end{array}$ & RAIS & $\begin{array}{l}\text { Choudhry (2009) } \\
\text { Glaeser e Resseger (2010) }\end{array}$ \\
\hline $\begin{array}{l}\text { Índice de consumo elétrico } \\
\text { industrial e comercial }\end{array}$ & $\begin{array}{l}\text { Consumo de energia elétrica } \\
\text { dividido pelo número de } \\
\text { estabelecimentos por setor } \\
\text { (indústria e comércio). Usado como } \\
\text { proxy para o estoque de capital local } \\
\text { (infraestrutura de energia) }\end{array}$ & SEI & $\begin{array}{l}\text { Bronzini e Piselli (2009) } \\
\text { Schettini e Azzoni (2015) }\end{array}$ \\
\hline $\begin{array}{l}\text { Percentual da população } \\
\text { feminina ocupada }\end{array}$ & $\begin{array}{l}\text { Parcela de trabalhadores formais do } \\
\text { sexo feminino }\end{array}$ & RAIS & Bustelo et al. (2019) \\
\hline Densidade populacional & $\begin{array}{c}\text { População dividida pela área } \\
\text { municipal }\left(\mathrm{em} \mathrm{km}^{2}\right)\end{array}$ & IBGE & Glaeser e Resseger (2010) \\
\hline Densidade do emprego & $\begin{array}{l}\text { Razão entre o emprego formal do } \\
\text { município e a sua área territorial } \\
\left(\mathrm{em} \mathrm{km}^{2}\right)\end{array}$ & RAIS/IBGE & $\begin{array}{l}\text { Ciccone e Hall (1996) } \\
\text { Glaeser e Resseger (2010) } \\
\text { de Almeida et al. (2017) }\end{array}$ \\
\hline $\begin{array}{l}\text { Percentual da população } \\
\text { formal ocupada na Adm. } \\
\text { Pública }\end{array}$ & $\begin{array}{l}\text { Parcela de trabalhadores formais } \\
\text { empregada na Administração } \\
\text { Pública }\end{array}$ & RAIS & $\begin{array}{l}\text { Faggio e Overman (2014) } \\
\text { Loyo et al. (2018) }\end{array}$ \\
\hline $\begin{array}{l}\text { Proporção de famílias } \\
\text { beneficiadas pelo } \\
\text { Bolsa Família* }\end{array}$ & $\begin{array}{l}\text { Número de benefícios concedidos, } \\
\text { em dezembro de cada ano, dividido } \\
\text { pela população municipal, } \\
\text { multiplicado por } 100 .\end{array}$ & $\begin{array}{l}\text { Ministério da } \\
\text { Cidadania }\end{array}$ & $\begin{array}{l}\text { Freguglia et al. (2018) } \\
\text { Correa Junior et al. (2019) }\end{array}$ \\
\hline $\begin{array}{l}\text { Índice de concentração } \\
\text { /especialização } \\
\text { setorial espacial }\end{array}$ & $\begin{array}{l}\text { Quociente locacional (QL) definido } \\
\text { a partir do número de trabalhadores } \\
\text { por setor CNAE-95 }\end{array}$ & RAIS & $\begin{array}{l}\text { Raiher e Candido (2018) } \\
\text { Raiher (2020) }\end{array}$ \\
\hline $\begin{array}{l}\text { Índice de diversificação } \\
\text { espacial }\end{array}$ & $\begin{array}{l}\text { Indice de Hirschman-Herfindahl } \\
\text { Modificado (HHM) definido a partir } \\
\text { do número de trabalhadores por setor } \\
\text { CNAE } 1.0 \text { (serviços, indústria de } \\
\text { transformação e agropecuária) }\end{array}$ & RAIS & $\begin{array}{l}\text { Raiher e Candido (2018) } \\
\text { Raiher (2020) }\end{array}$ \\
\hline $\begin{array}{l}\text { Faixas de tamanho } \\
\text { populacional }\end{array}$ & $\begin{array}{l}\text { Variáveis dummies para as faixas de } \\
\text { tamanho populacional municipal: } \\
\text { i) Faixa 1: população acima de } 50 \\
\text { mil e até } 100 \text { mil habitantes } \\
\text { ii) Faixa 2: população acima de } 100 \\
\text { mil e até } 500 \text { mil habitantes } \\
\text { iii) Faixa 3: população acima de } 500 \\
\text { mil habitantes } \\
\text { Categoria de referência na regressão: } \\
\text { municípios com até } 50 \text { mil habitantes }\end{array}$ & IBGE & Glaeser e Resseger (2010) \\
\hline
\end{tabular}

Fonte: Elaboração própria com base nos dados da pesquisa. *Período de 2004 a 2016. 


\subsection{Modelo econométrico e método de estimação}

Blundell e Bond (2000) analisaram o problema de identificação em modelos que possuem persistência temporal em um painel dinâmico ao mostrar que as variáveis de vendas, o capital e o trabalho são altamente persistentes. O estudo comparou diferentes estratégias de identificação para estimar uma função de produção no nível das firmas industriais dos Estados Unidos, em um modelo de painel dinâmico que possui um número pequeno de períodos de tempo. O GMM em primeira diferença eliminou os efeitos específicos não observados e usa variáveis defasadas como instrumentos para a simultaneidade da equação diferenciada. No entanto, a baixa correlação das taxas de crescimento corrente da produção, do capital e do trabalho com as suas defasagens em nível resultaram em um problema de instrumentos fracos na estimação com o GMM em primeira diferença.

O uso de instrumentos adicionais, através do método GMM System, permitiu reduzir substancialmente o viés de amostras finitas que deriva do uso do estimador de GMM em primeira diferença para modelos autorregressivos com persistência temporal e painel curto. Particularmente, o GMM System usa as defasagens das variáveis em diferenças como instrumentos para a equação em nível, em adição ao uso das defasagens em nível como instrumentos para a equação em diferenças. Nesse sentido, o estimador incorpora condições de momento mais informativas, que são válidas sob razoáveis restrições de estacionariedade em relação às condições iniciais.

Neste estudo, estimou-se o modelo econométrico utilizando um painel dinâmico, de modo a considerar a influência da produtividade defasada temporalmente $\left(t_{-1}\right)$ sobre o seu comportamento atual $(t)$. O método de estimação adotado foi o GMM (Método dos Momentos Generalizados), com o uso de variáveis instrumentais em dois estágios. Blundell e Bond (1998) desenvolveram o estimador GMM System, o qual consiste na estimação de um sistema empilhado de equações em nível e em diferença, de modo a lidar com o problema de instrumentos fracos em painéis curtos e com o problema dos efeitos não observados invariantes no tempo.

O estudo adotará o estimador GMM System para lidar com o problema de endogeneidade da variável dependente defasada e dos fatores não observados municipais (fixos no tempo). O GMM System, assim como os estimadores desenvolvidos por HoltzEakin et al. (1988), Arellano e Bond (1991) e Arellano e Bover (1995), é indicado para dados em painel com um pequeno intervalo temporal e muitas observações ("small $t$, large $N$ ”). O estimador GMM para painel dinâmico é indicado quando as variáveis independentes podem não ser estritamente exógenas. Em outras palavras, elas podem estar correlacionadas com resultados no passado e possivelmente erros atuais e quando há presença de efeitos fixos, heteroscedasticidade e autocorrelação. O GMM System em Dois Estágios utiliza as defasagens em nível da variável dependente e das explicativas exógenas como instrumentos para o modelo em diferenças e as defasagens das diferenças como instrumentos para o modelo em nível. 
Portanto, o modelo econométrico deste estudo é definido a partir da seguinte especificação:

$$
y_{i t}=\alpha y_{i, t-1}+\beta^{\prime} X_{i t}+\gamma^{\prime} A_{i t}+\eta_{i}+\delta_{t}+v_{i t}
$$

em que $i=1, \ldots, N$ representa o indicador do município e $t=1, \ldots, T$ representa o período de tempo analisado (2002-2016). Assim, $y_{i t}$ é a produtividade do trabalho do município $i$ no período $t, y_{i, t-1}$ é o nível da produtividade do trabalho defasado, implicando que a produtividade apresentada no ano anterior tem efeito sobre a produtividade do trabalho do ano seguinte (path dependence). A aglomeração $A_{i t}$ representa um conjunto de variáveis que serão adotadas para mensurar os efeitos das externalidades de aglomeração nos mercados de trabalho locais: faixas de tamanho da população (acima de 50 e até 100 mil habitantes, acima de 100 e até 500 mil, e acima de 500 mil habitantes), densidade populacional, densidade do emprego e indicadores de especialização e diversificação setorial. $\eta_{i}$ é o efeito não observado, ou a heterogeneidade em cada município, $\delta_{t}$ são dummies anuais, $v_{i t}$ é o termo de erro e, por fim, $X_{i t}$ é o conjunto de variáveis utilizadas como controles para os fatores explicativos locais da produtividade do trabalho.

O estudo adotou o conceito de produtividade do trabalho baseado em Squeff e De Negri (2014), no qual a produtividade foi calculada pela razão entre o valor adicionado a preços constantes de 2016, deflacionados pelo IGP-M, e o número de trabalhadores ocupados formais, conforme a Equação 2:

$$
\operatorname{ProdTrab} b_{t}^{i}=\frac{Y_{t}^{i}}{L_{t}^{i}}
$$

Assim, $Y$ é equivalente ao valor adicionado, a preços constantes de 2016, e $L$ é o número de empregos formais. O subscrito $t$ representa o ano e $i$ indica o município.

A nível internacional, Conti (2005); Garofalo et al. (2008) e Lokshin et al. (2008) utilizaram dados em painel e o método GMM System para estimar a produtividade do trabalho ou efeitos de indicadores sobre o crescimento da produtividade. Nacionalmente, Raiher (2020) estimou os efeitos das economias de aglomeração (localização e urbanização) sobre a produtividade industrial dos municípios do Brasil, entre 2010 e 2017, usando um painel dinâmico espacial com efeito fixo de municípios e o estimador de GMM System. O estudo apontou que, quando as variáveis dependente e explicativa apresentam forte persistência temporal, o estimador GMM System mostra-se o mais indicado para a estimação consistente por combinar um conjunto de equações em 
diferença e em nível e usar as variáveis defasadas em nível como instrumentos para o primeiro grupo e as defasagens das diferenças como instrumentos para o segundo grupo.

Por fim, Moura et al. (2020) utilizaram um painel dinâmico para estimar os fatores explicativos do crescimento econômico (PIB per capita) entre os municípios do estado de Alagoas, usando dados de 2000 a 2015 e o método GMM System. Os autores apontam que o painel estático pode ser insuficiente para observar a dimensão temporal e lidar com problemas de endogeneidade em alguns modelos, o que sugere a necessidade de levar em consideração a natureza dinâmica da variável em análise. Esse comportamento dinâmico, em geral, é a justificativa adotada em grande parte dos estudos empíricos sobre a produtividade e o crescimento, tais como os citados acima, para o uso de um painel dinâmico e do respectivo estimador de GMM System tal como sugerido em (Blundell e Bond, 1998).

\subsection{Indicadores de concentração e diversificação}

Para mensurar o papel das economias de aglomeração sobre a produtividade do trabalho local, foram utilizados indicadores de concentração (economias de localização) e diversificação (economias de urbanização) setoriais, aqui considerados agropecuária, indústria e serviços. Como apresentado por Raiher e Candido (2018) e Raiher (2020), este estudo adotará uma versão modificada do índice de HirschmanHerfindahl (HHM) ${ }^{2}$ definida como:

$$
\begin{gathered}
H H_{i t}=\sum_{j=1}^{n}\left[\left(\frac{E_{i j t}}{E_{i t}}\right)-\left(\frac{E_{j t}}{E_{p t}}\right)\right]^{2} \\
H H M_{i t}=1-H H_{i t}
\end{gathered}
$$

em que HH representa o índice Hirschman-Herfindahl normalizado (Henderson, 1999, 2003), ou o índice de concentração setorial (varia de 0 a 2, quanto maior mais concentrado ou especializado), $E_{i j t}$ é o emprego no município $i$, no subsetor $j$, no ano $t$; $E_{i t}$ é o emprego setorial total do município $i$, no ano $t ; E_{j t}$ é o emprego no subsetor $j$ do estado da Bahia, no ano $t ; E_{p t}$ é o total do emprego setorial na Bahia, no ano $t ; n$ é o número de subsetores em cada setor (agropecuária, indústria e serviços). Nesse sentido, a Equação (4) mede a diversificação setorial espacial, assim, quanto maior o valor apresentado pelo coeficiente, mais diversificada potencialmente é a estrutura setorial.

Considerou-se o nivel de concentração ou especialização setorial espacial a partir do seguinte indicador de especialização locacional (Quociente Locacional):

\footnotetext{
${ }^{2}$ A versão é baseada no índice de Hirschman-Herfindahl normalizado (HENDERSON, 1999; 2003).
} 


$$
Q L_{i j t}=\left[\frac{\left(\frac{E_{i j t}}{E_{i t}}\right)}{\left(\frac{E_{j t}}{E_{p t}}\right)}\right]
$$

Portanto, o Quociente Locacional (QL) e o indicador Hirschman-Herfindahl Modificado (HHM) são utilizados para mensurar os níveis de especialização (ou localização) e diversificação (ou urbanização), respectivamente. No que tange ao HHM, quanto maior é o seu valor, mais desconcentrada (ou diversificada) será a atividade produtiva analisada. O índice de diversificação HHM é relacionando ao grau de concorrência entre empresas de um setor, assim, está diretamente conectado com as economias de aglomeração decorrentes dos efeitos espaciais da urbanização (Raiher e Candido, 2018).

Já o QL indica a concentração relativa de uma determinada atividade produtiva em uma região (município) comparativamente à participação produtiva desse mesmo setor no espaço definido como base (o estado da Bahia, no caso deste estudo). Dessa forma, o índice QL mensura economias de localização baseadas na concentração de atividades econômicas similares em um determinado espaço, o que pode intensificar o processo de transbordamentos tecnológicos intraindústria (Marshall, 1890). No entanto, ao se obter um coeficiente locacional elevado (maior do que a unidade), em um determinado setor em uma região, isso significa que há uma especialização da estrutura de produção local (Suzigan et al., 2003). Os indicadores de diversificação foram construídos com base na classificação da CNAE-95 (CNAE 1.0, divisão de 2 dígitos), enquanto o QL usou a seção CNAE-95 para calcular o indicador dos setores de indústria, serviços e agropecuária.

Foram utilizadas classificações diferentes para o QL e o HMM, pois os indicadores possuem níveis de sensibilidade diferentes. O QL faz uma análise para cada setor individualmente, ou seja, não realiza uma soma dos subsetores como faz o HHM. Assim, a desagregação do QL introduziria muitos subsetores na regressão e isso reduziria os graus de liberdade do modelo na estimação. Além disso, a decomposição do indicador comprometeria o cálculo no nível municipal, já que se teria uma quantidade grande de municípios sem emprego formal em determinado subsetor e se perderiam esses municípios na estimação. Destaca-se, mais uma vez, que os indicadores foram construídos levando em consideração apenas o trabalho formal.

\section{Resultados e discussão}

\subsection{Análise descritiva dos dados}

Nas Tabelas 1 e 2, apresentamos as estatísticas descritivas para os grupos de municípios fora do Semiárido e os pertencentes à região. As descritivas apresentadas correspondem às variáveis do modelo econométrico, no mesmo formato em que serão utilizadas na regressão. Assim, no grupo de municípios fora do Semiárido, tem-se 
um maior nível médio de produtividade do trabalho (em log), um maior percentual de firmas médias, maiores consumos de energia elétrica na indústria e comércio, as densidades populacional e do emprego são maiores.

Tabela 1. Estatísticas descritivas para os municípios fora do semiárido

\begin{tabular}{|c|c|c|c|c|c|}
\hline Variável & Obs. & Média & Desvio & Min. & Máx. \\
\hline Log. da produtividade agregada & 2.278 & 5,31 & 1,33 & 2,83 & 10,98 \\
\hline \% de firmas médias & 2.280 & 3,55 & 3,19 & 0,00 & 30,77 \\
\hline$\%$ de firmas grandes & 2.280 & 2,06 & 2,07 & 0,00 & 20,00 \\
\hline $\begin{array}{l}\% \text { de trabalhadores com ensino funda- } \\
\text { mental }\end{array}$ & 2.280 & 8,98 & 5,68 & 0,23 & 69,25 \\
\hline$\%$ de trabalhadores com ensino médio & 2.280 & 44,78 & 13,79 & 0,78 & 84,18 \\
\hline $\begin{array}{l}\% \text { de trabalhadores com ensino supe- } \\
\text { rior }\end{array}$ & 2.280 & 8,58 & 7,64 & 0,00 & 91,02 \\
\hline $\begin{array}{l}\text { Log. do consumo de energia na indús- } \\
\text { tria }\end{array}$ & 2.078 & 11,03 & 1,72 & 3,95 & 16,60 \\
\hline $\begin{array}{l}\text { Log. do consumo de energia no comér- } \\
\text { cio }\end{array}$ & 2.267 & 10,10 & 0,68 & 6,03 & 13,75 \\
\hline$\%$ de trabalhadores do sexo feminino & 2.280 & 44,76 & 10,67 & 1,82 & 76,52 \\
\hline Log. da densidade populacional & 2.280 & 3,71 & 1,31 & $-0,09$ & 8,37 \\
\hline Log. da densidade do emprego & 2.280 & 1,18 & 1,59 & $-4,53$ & 7,79 \\
\hline \% do emprego público & 2.280 & 49,01 & 23,63 & 0,00 & 99,23 \\
\hline $\begin{array}{l}\text { Proporção, na população, de famílias } \\
\text { no Bolsa Família }\end{array}$ & 1.976 & 11,77 & 6,05 & 0,03 & 57,73 \\
\hline Îndice QL da agropecuária & 2.280 & 3,28 & 3,39 & 0,00 & 18,51 \\
\hline Índice QL da indústria & 2.280 & 0,76 & 0,97 & 0,00 & 5,68 \\
\hline Îndice QL dos serviços & 2.280 & 1,02 & 0,31 & 0,01 & 1,71 \\
\hline Índice HHM da agropecuária & 2.262 & 0,91 & 0,23 & $-0,75$ & 1,00 \\
\hline Índice HHM da indústria & 1.997 & 0,51 & 0,26 & $-0,09$ & 0,98 \\
\hline Îndice HHM dos serviços & 2.280 & 0,81 & 0,11 & $-0,04$ & 1,00 \\
\hline $\begin{array}{l}\text { Faixa populacional: municipios com } \\
\text { mais de } 50 \text { mil e até } 100 \text { mil habitantes }\end{array}$ & 2.280 & 0,06 & 0,23 & 0,00 & 1,00 \\
\hline $\begin{array}{l}\text { Faixa populacional: municípios com } \\
\text { mais de } 100 \text { mil e até } 500 \text { mil habitan- } \\
\text { tes }\end{array}$ & 2.280 & 0,06 & 0,24 & 0,00 & 1,00 \\
\hline $\begin{array}{l}\text { Faixa populacional: municipios com } \\
\text { mais de } 500 \text { mil habitantes }\end{array}$ & 2.280 & 0,01 & 0,08 & 0,00 & 1,00 \\
\hline
\end{tabular}

Fonte: Elaboração própria com base nos dados da pesquisa.

Nos municípios que compõem o Semiárido, a participação feminina no mercado formal de emprego é maior, em média 53,5\%. Notadamente, o percentual de empregos no setor público no Semiárido e o percentual de famílias beneficiárias do Bolsa Família são maiores do que nos municípios fora do Semiárido, o que já indica uma 
dependência relevante da esfera pública nos municípios mais pobres. Os percentuais educacionais não variaram muito entre as duas regiões, o que pode ser parcialmente explicado pela menor heterogeneidade dentro do mercado de trabalho formal. Os indicadores de especialização e concentração apresentaram resultados diversos, de acordo com o setor em análise. Como esperado, para as dummies de faixas populacionais, em média, os maiores municípios estão localizados fora do Semiárido da Bahia.

Tabela 2. Estatísticas descritivas para os municípios do semiárido

\begin{tabular}{|c|c|c|c|c|c|}
\hline Variável & Obs. & Média & Desvio & Min. & Máx. \\
\hline Log. da produtividade agregada & 3.975 & 4,66 & 0,90 & 2,78 & 9,38 \\
\hline$\%$ de firmas médias & 3.975 & 2,28 & 2,79 & 0,00 & 33,33 \\
\hline$\%$ de firmas grandes & 3.975 & 2,90 & 3,00 & 0,00 & 50,00 \\
\hline $\begin{array}{l}\text { \% de trabalhadores com ensino funda- } \\
\text { mental }\end{array}$ & 3.975 & 7,94 & 5,66 & 0,00 & 83,36 \\
\hline$\%$ de trabalhadores com ensino médio & 3.975 & 49,66 & 14,51 & 0,00 & 100,00 \\
\hline $\begin{array}{l}\% \text { de trabalhadores com ensino supe- } \\
\text { rior }\end{array}$ & 3.975 & 8,62 & 8,94 & 0,00 & 94,72 \\
\hline $\begin{array}{l}\text { Log. do consumo de energia na indús- } \\
\text { tria }\end{array}$ & 3.132 & 10,59 & 1,45 & 3,35 & 17,36 \\
\hline $\begin{array}{l}\text { Log. do consumo de energia no comér- } \\
\text { cio }\end{array}$ & 3.954 & 9,90 & 0,51 & 6,53 & 12,67 \\
\hline$\%$ de trabalhadores do sexo feminino & 3.973 & 53,54 & 10,54 & 1,76 & 82,93 \\
\hline Log. da densidade populacional & 3.975 & 2,93 & 0,83 & 0,38 & 6,14 \\
\hline Log. da densidade do emprego & 3.975 & $-0,15$ & 1,14 & $-6,32$ & 4,53 \\
\hline \% do emprego público & 3.975 & 66,76 & 23,77 & 0,00 & 99,65 \\
\hline $\begin{array}{l}\text { Proporção, na população, de famílias } \\
\text { no Bolsa Família }\end{array}$ & 3.445 & 13,15 & 6,11 & 0,07 & 88,51 \\
\hline Îndice QL da agropecuária & 3.975 & 1,40 & 2,56 & 0,00 & 20,07 \\
\hline Îndice QL da indústria & 3.975 & 0,58 & 0,95 & 0,00 & 7,42 \\
\hline Índice $\mathrm{QL}$ dos serviços & 3.975 & 1,23 & 0,32 & 0,03 & 1,72 \\
\hline Índice HHM da agropecuária & 3.578 & 0,95 & 0,14 & $-0,62$ & 1,00 \\
\hline Índice HHM da indústria & 2.870 & 0,42 & 0,27 & $-0,09$ & 0,99 \\
\hline Îndice HHM dos serviços & 3.975 & 0,77 & 0,12 & $-0,29$ & 1,00 \\
\hline $\begin{array}{l}\text { Faixa populacional: municípios com } \\
\text { mais de } 50 \text { mil e até } 100 \text { mil habitantes }\end{array}$ & 3.975 & 0,07 & 0,26 & 0,00 & 1,00 \\
\hline $\begin{array}{l}\text { Faixa populacional: municípios com } \\
\text { mais de } 100 \text { mil e até } 500 \text { mil habitan- } \\
\text { tes }\end{array}$ & 3.975 & 0,01 & 0,12 & 0,00 & 1,00 \\
\hline $\begin{array}{l}\text { Faixa populacional: municipios com } \\
\text { mais de } 500 \text { mil habitantes }\end{array}$ & 3.975 & 0,00 & 0,06 & 0,00 & 1,00 \\
\hline
\end{tabular}

Fonte: Elaboração própria com base nos dados da pesquisa. 
A Figura 1 representa a evolução da produtividade do trabalho na Bahia ${ }^{3}$. A produtividade agregada (a partir das setoriais) na Figura 1(a) apresentou um comportamento praticamente constante no decorrer do período em análise. Para os municípios fora do Semiárido, a produtividade do setor de serviços apresentou uma maior evolução ao longo do tempo ${ }^{4}$. A indústria apresentou uma leve evolução positiva a partir de 2011, ultrapassando a produtividade da agropecuária. Na Figura 1(b), é possível observar que a produtividade do setor de serviços teve uma evolução positiva considerável no Semiárido baiano, principalmente a partir de 2009. No entanto, esse comportamento não se sustentou, decrescendo em 2014. As demais produtividades setoriais não diferem muito entre os grupos de municípios.

É importante destacar que o setor de serviços foi o único que apresentou crescimento expressivo da produtividade no estado. O setor ampliou sua participação no VAB de 64,5\% em 2006 para 70,5\% em 2015, no entanto o número de ocupados ou o ganho salarial não aumentou na mesma proporção (Freitas Merelles e Santos, 2018). O crescimento do setor de serviços na economia baiana acompanha a tendência nacional. Sousa Filho et al. (2020) mostram que a participação do VAB de serviços na economia brasileira evoluiu de forma acentuada desde 1990, após maior liberalização do comércio.

As produtividades agregadas do Semiárido e dos municípios de fora do Semiárido baiano apresentam uma tendência de baixo crescimento ou estagnação, um comportamento que tem sido identificado para o Brasil (Squeff e De Negri, 2014). Tal resultado aponta a necessidade de maior agregação de valor adicionado na produção baiana. A formulação de políticas que estimulem a diversificação da produção local no médio e longo prazo ainda é empecilho forte para o desenvolvimento produtivo na Bahia. No entanto, uma vez que as decisões de localização das empresas levem em conta os diferenciais de custos por setor e região, é importante fortalecer os fatores que são atrativos para os setores de maior valor agregado.

Ademais, como pode ser visto na Figura 2, a região do Semiárido ocupa a maior parte do território baiano, 64\% (IBGE, 2017). Aproximadamente 42,9\% da população baiana vive abaixo da linha da pobreza (IBGE, 2018). A baixa qualificação profissional e a informalidade do mercado de trabalho baiano se constituem grandes empecilhos para o avanço da produtividade do trabalho no estado. De acordo com o IBGE (2018), a informalidade do trabalho na Bahia atingiu 56,7\% da população ocupada, mais de 3,3 milhões de pessoas trabalhavam por conta própria. Esse cenário contribui para o aumento das desigualdades regionais dentro do estado da Bahia.

\footnotetext{
${ }^{3}$ Os gráficos apresentam os valores em $\log$ da produtividade do trabalho total e setorial, pois a variável dependente nos modelos assume o mesmo formato.

${ }^{4}$ A definição de produtividade adotada levou em consideração apenas a relação VAB/Empregos formais. Nesse sentido, há uma limitação em termos conceituais. Portanto, a elevação da produtividade em um setor pode indicar o aumento do $\mathrm{VAB}$ em relação ao número de empregos formais ou a diminuição de empregos.
} 
Figura 1. Evolução da produtividade do trabalho na Bahia (em log)

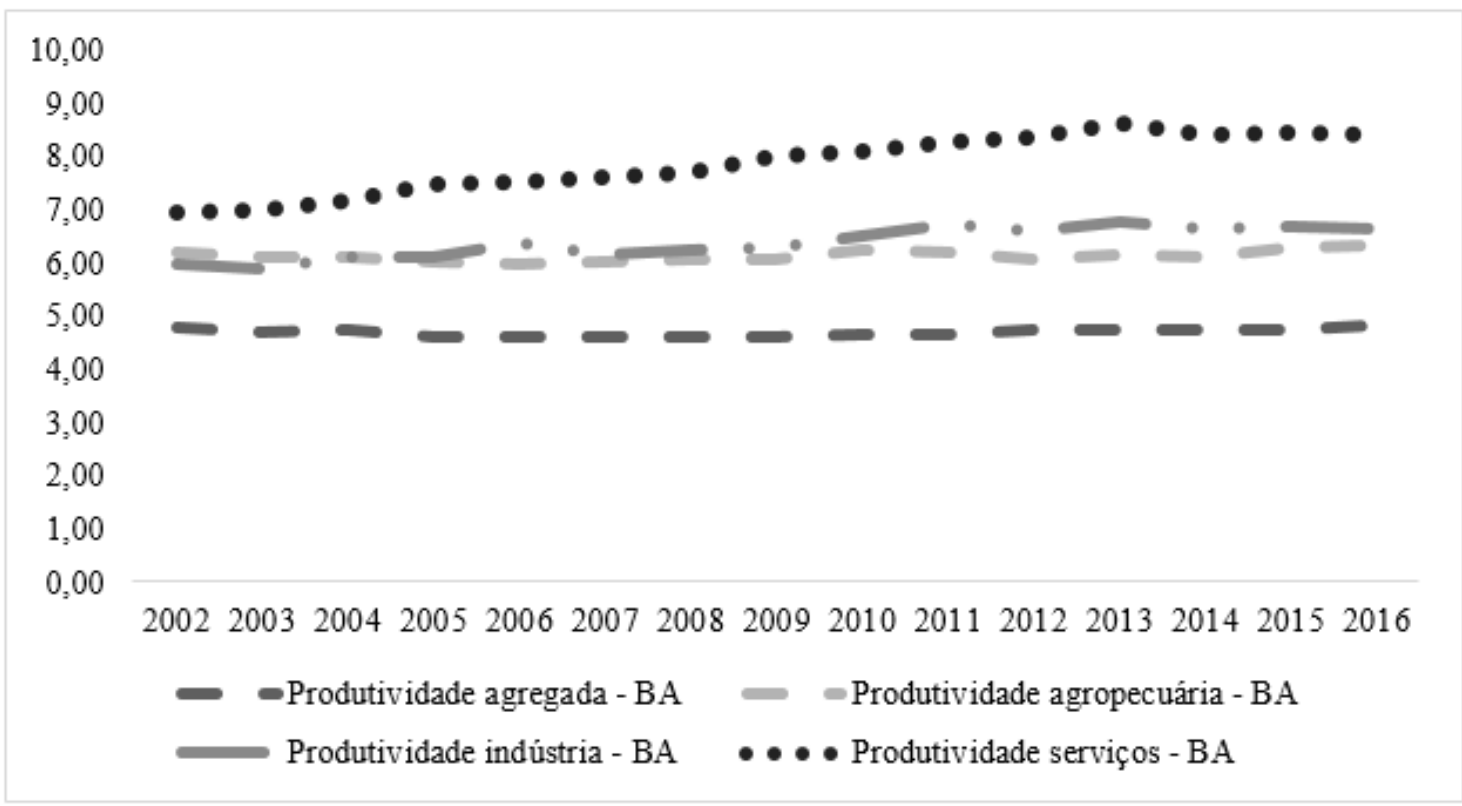

(a) Produtividade do trabalho setorial nos municípios da Bahia fora do Semiárido

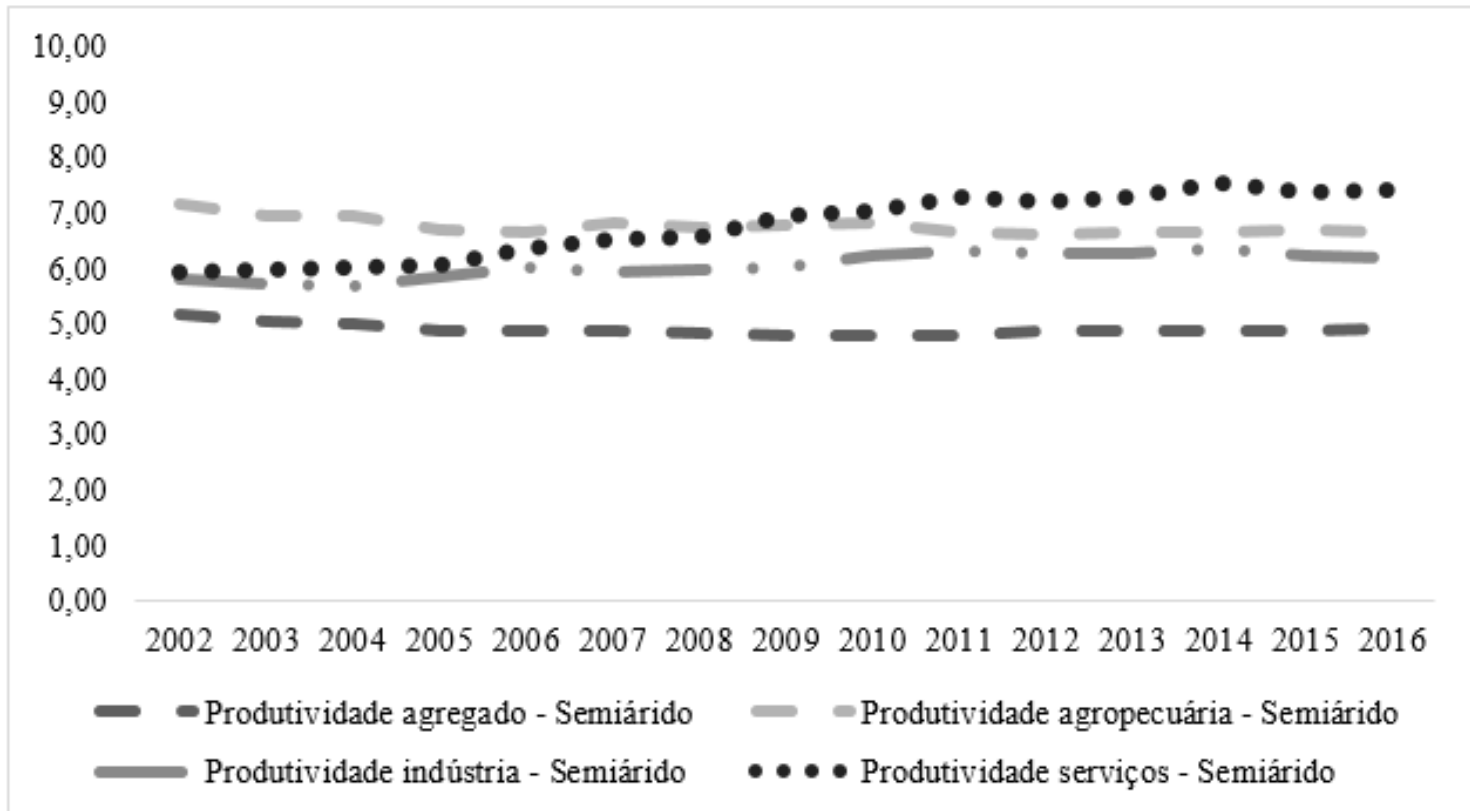

(b) Produtividade do trabalho setorial nos municípios do Semiárido da Bahia

Fonte: Elaboração própria com base nos dados da pesquisa. 
Figura 2. Mapa do estado da Bahia destacando os municípios pertencentes à região do Semiárido

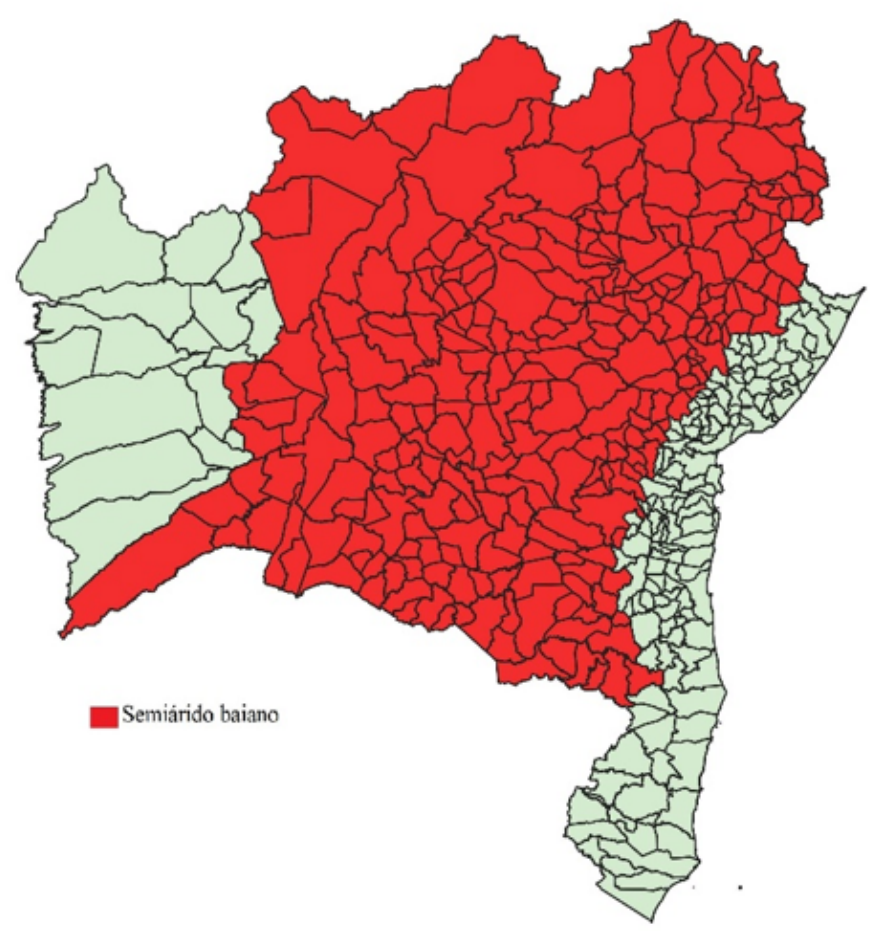

Fonte: Elaboração própria. Definição da SUDENE, 2007.

\subsection{Indicadores regionais de concentração e diversificação produtiva}

A maior parte dos municípios baianos fica no Semiárido, região mais pobre do estado e com a economia essencialmente baseada em transferências de renda ou no setor público. Por outro lado, os municípios localizados na região oeste do estado e na região metropolitana de Salvador possuem os melhores indicadores econômicos em função das atividades que exercem, voltadas para o agronegócio e a indústria, respectivamente. Na região oeste do estado, encontra-se o município de Barreiras, um importante polo produtor de algodão e soja nacional. As Figuras 3 e 4 indicam esse fato.

De acordo com a Figura 3, que apresenta o indicador de concentração setorial relativa do emprego $(\mathrm{QL})$, o setor de serviços é o mais predominante no estado. É perceptível a força da agropecuária nas regiões oeste, sul e extremo sul. Em 2002, o valor máximo do indicador de concentração na agropecuária era de 16,6. Esse número passou para 19,4 em 2016. Poucas variações produtivas ocorreram com a indústria na Bahia, ainda concentrando-se nas regiões metropolitanas de Salvador, Feira de Santana e no sudoeste do estado. O setor de serviços cresceu no interior do estado, passando a representar a maior ocupação em termos de trabalho formal setorial em grande parte dos municípios interioranos. 


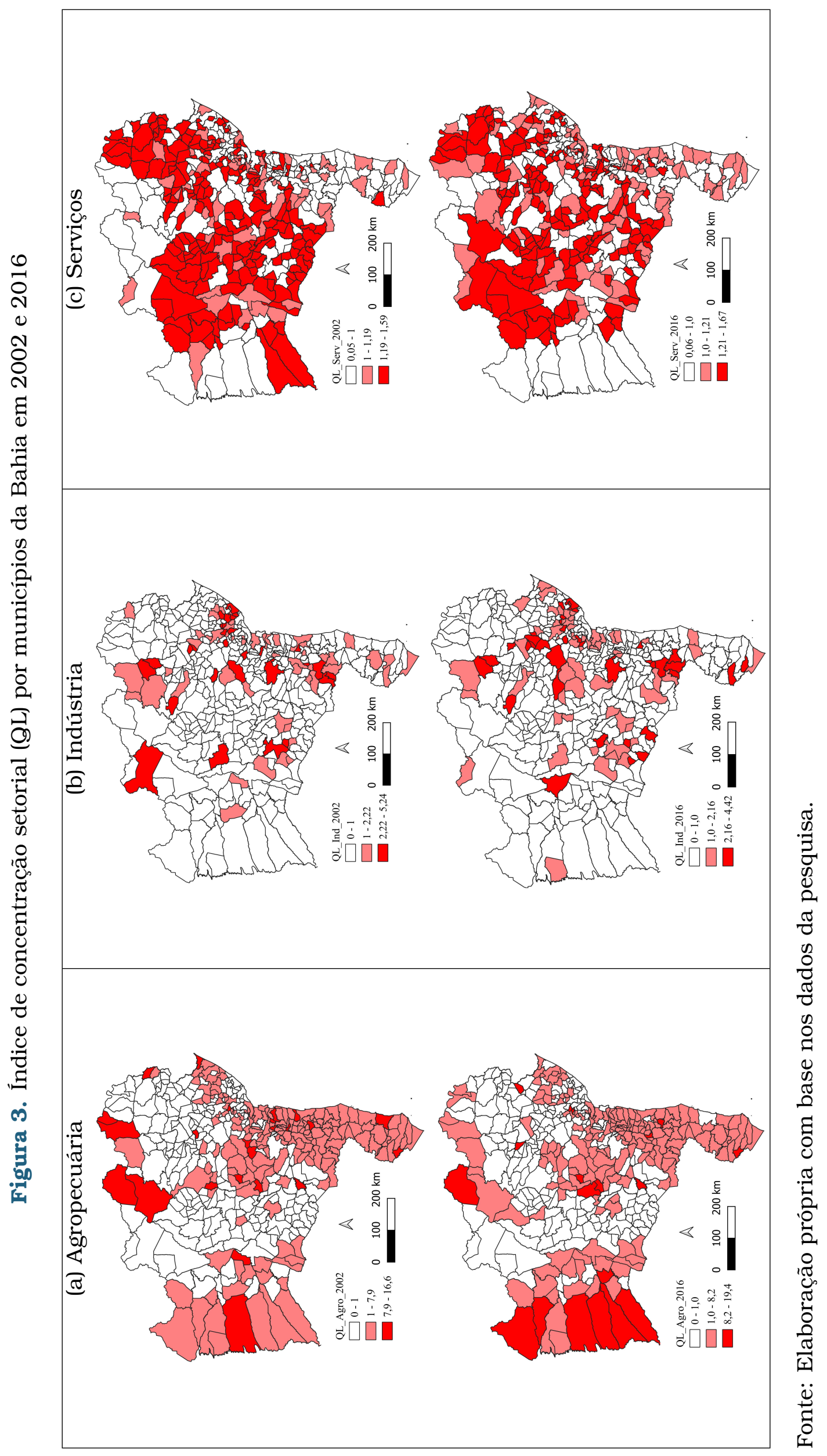




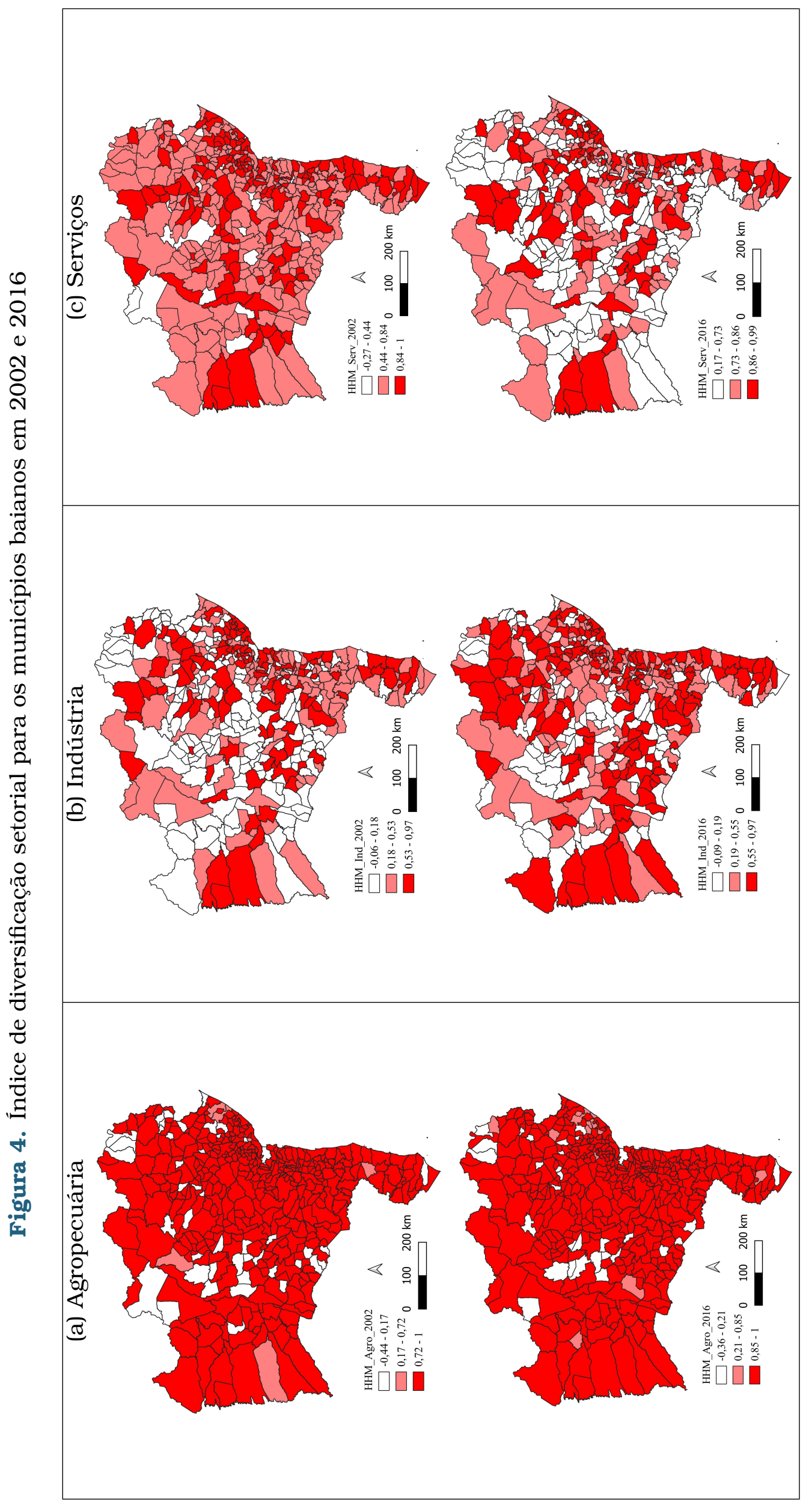

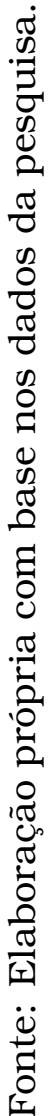


No índice de diversificação setorial, apresentado na Figura 4, é interessante destacar como a espacialização do indicador envolve grande parte dos municípios baianos. $\mathrm{O}$ interior do estado foi marcado pelo avanço dos pequenos e médios negócios e também pelo incentivo à agricultura familiar ao longo dos anos 2000. Isso pode ser um empecilho para o desenvolvimento setorial do interior do estado. Assim, municípios de renda baixa e média tendem a ficar estagnados economicamente, caso não haja políticas de desenvolvimento regional eficientes focadas nas potencialidades locais.

\subsection{Produtividade do trabalho nos municipios do estado da Bahia e eco- nomias de aglomeração}

O presente trabalho estimou sete regressões para o modelo de produtividade do trabalho em nível municipal, utilizando o método GMM System em painel dinâmico. As estimações foram feitas considerando dois grupos: os municípios fora da região do Semiárido (Grupo 1) e os municípios da região do Semiárido (Grupo 2) ${ }^{5}$. O objetivo dessa divisão regional foi captar os diferentes efeitos das variáveis sobre os padrões de produtividade dos municípios baianos. Além dos fatores tradicionais que contribuem para o movimento de aglomeração e de economias de escala, como a demanda e a oferta de bens públicos (Fugita, 1988; Abdel-Rahman, 1988), investigou-se o efeito das aglomerações populacionais (tamanho das cidades) e do emprego (densidade) sobre a produtividade do trabalho.

No que se refere às estatísticas apresentadas, o teste de Hansen busca fornecer evidências sobre a exogeneidade dos instrumentos usados no modelo. Em relação ao Grupo 1, o p-valor do teste de Hansen indica a não rejeição da hipótese nula do teste em todas as especificações estimadas, cuja hipótese nula é de exogeneidade dos instrumentos. Por outro lado, para o Grupo 2, o teste indicou a rejeição da hipótese nula. No entanto, é importante ressaltar que a rejeição da hipótese de exogeneidade apenas indica que algum dos instrumentos pode ser fraco sem ser possivel identificar qual deles possui a limitação (Cameron e Trivedi, 2005).

Na Tabela 3, têm-se as estimações das regressões de produtividade do trabalho para os municípios do Grupo 1. Nessa regressão, os resultados indicam que no modelo que contém apenas um conjunto inicial de variáveis socioeconômicas - SGMM1 - a produtividade passada está associada com um crescimento de 0,34\% na produtividade corrente. Na medida em que adicionamos mais variáveis de controle, esse percentual aumenta. Ao adicionar os índices de diversificação (HHM) e especialização (QL) setoriais - correspondendo à coluna SGMM5 -, esse efeito aumenta para 0,47\%. É importante destacar que dos modelos SGMM5 a SGMM7 os parâmetros da produtividade do trabalho apresentaram um maior nível de significância. No entanto, os

\footnotetext{
${ }^{5}$ Adicionalmente, foi estimado o modelo completo, com todos os municípios, incluindo uma variável dummy indicando se o município pertence ao semiárido. A 5\% de significância, foi possivel afirmar que existem diferenças estatisticamente significativas entre os grupos. O resultado para a dummy do semiárido foi -0.19, o que indica que os municípios da região possuem, em média, uma produtividade do trabalho menor do que os municípios fora da região.
} 
coeficientes de especialização e diversificação não apresentaram um efeito positivo em sua maioria ou mesmo relevante para o aumento da produtividade. Para o grupo fora do Semiárido, o QL da indústria e dos serviços e o HHM dos serviços apresentaram efeitos negativos, enquanto no grupo do Semiárido o efeito negativo esteve presente no QL da indústria e dos serviços e no HHM dos três setores analisados.

Os resultados apresentados denotam que a diversificação do setor de serviços produz efeitos negativos e esses são mais intensos na região do Semiárido baiano (Tabela 4). Por sua vez, enquanto a diversificação da indústria contribuiu para a redução da produtividade do trabalho no Semiárido, não foi encontrado efeito para os municípios fora do Semiárido. Essas evidências vão na contramão dos achados por Raiher e Candido (2018), que encontraram um efeito relevante da urbanização (diversificação) para a produtividade dos municípios do Sul do Brasil, usando o mesmo nível de desagregação setorial, no entanto apenas para o setor industrial. É importante ressaltar as diferenças nos padrões de urbanização e de desenvolvimento entre as regiões consideradas, o que pode justificar os efeitos encontrados.

As proxies para a infraestrutura e estoque de capital local, representadas pelo consumo elétrico nos setores de comércio e indústria, apresentaram efeitos distintos. O consumo elétrico no setor do comércio mostrou um efeito positivo e significativo sobre a produtividade do trabalho em ambos os grupos. Já o consumo elétrico na indústria apresentou um efeito negativo e significativo para a Grupo 2. De acordo com Manso (2005), o PIB, a produtividade e o consumo de energia são fatores correlacionados. A produtividade do trabalho e o consumo elétrico explicam o crescimento do produto, o que faz desses elementos importantes variáveis para a elaboração de políticas econômicas. O autor sugere que, dentre essas variáveis, a produtividade é a mais relevante e, por isso, é um fator estratégico na elaboração de políticas.

Bronzini e Piselli (2009) encontraram um efeito positivo de 0,11\% e 0,19\% da infraestrutura pública, incluindo a energia elétrica, sobre a produtividade total, e do trabalho, respectivamente, nas regiões italianas, no período de 1980 e 2001. Por sua vez, Schettini e Azzoni (2015) mostram que a infraestrutura urbana, incluindo a energia, apresentou um efeito positivo sobre a eficiência produtiva regional do Brasil, usando dados da Pesquisa Industrial Anual (PIA) para o período de 2000 a 2010 . No entanto, a energia, isoladamente, não se mostrou significante para explicar o resultado. Considerando que o estudo analisou o setor industrial, esse resultado pode contribuir para explicar o efeito negativo do consumo de energia na indústria do Semiárido, observado nesse artigo. Ou seja, dadas as desigualdades regionais existentes na infraestrutura de energia, a oferta de energia local pode apresentar efeitos diferenciados setorialmente já que as requisições de infraestrutura produtiva são heterogêneas entre os setores e o seu peso pode ser maior na indústria. 


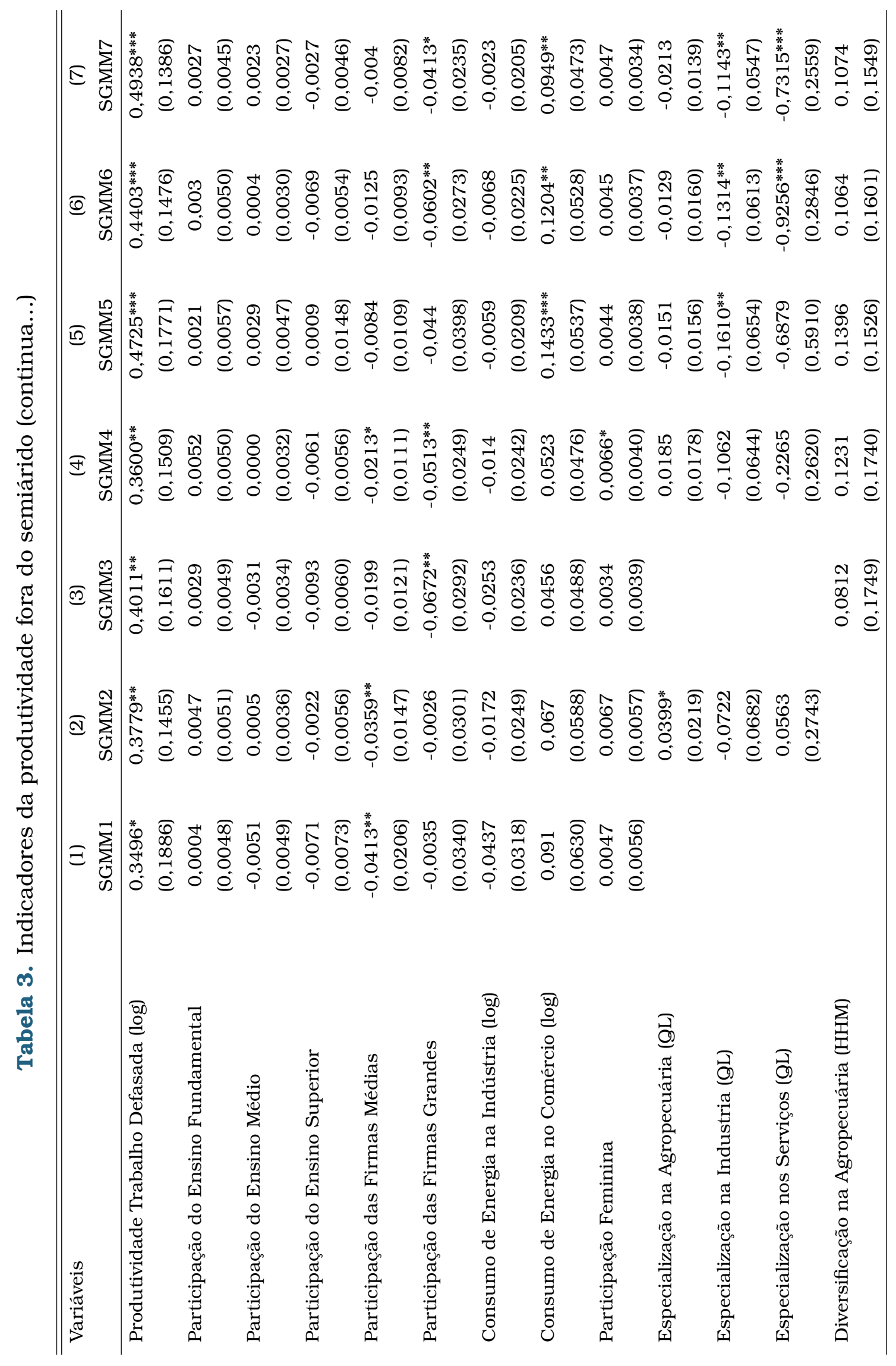




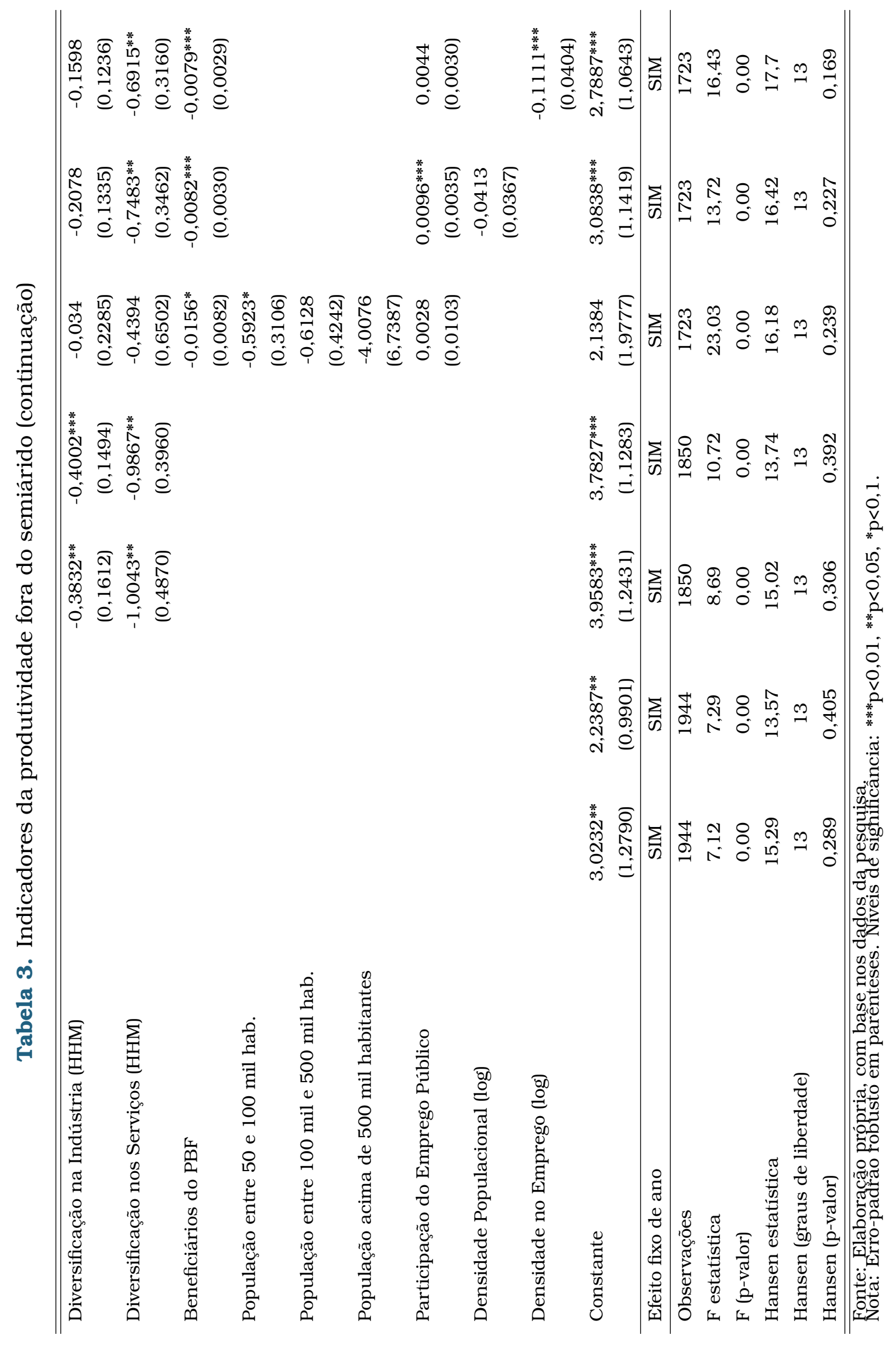




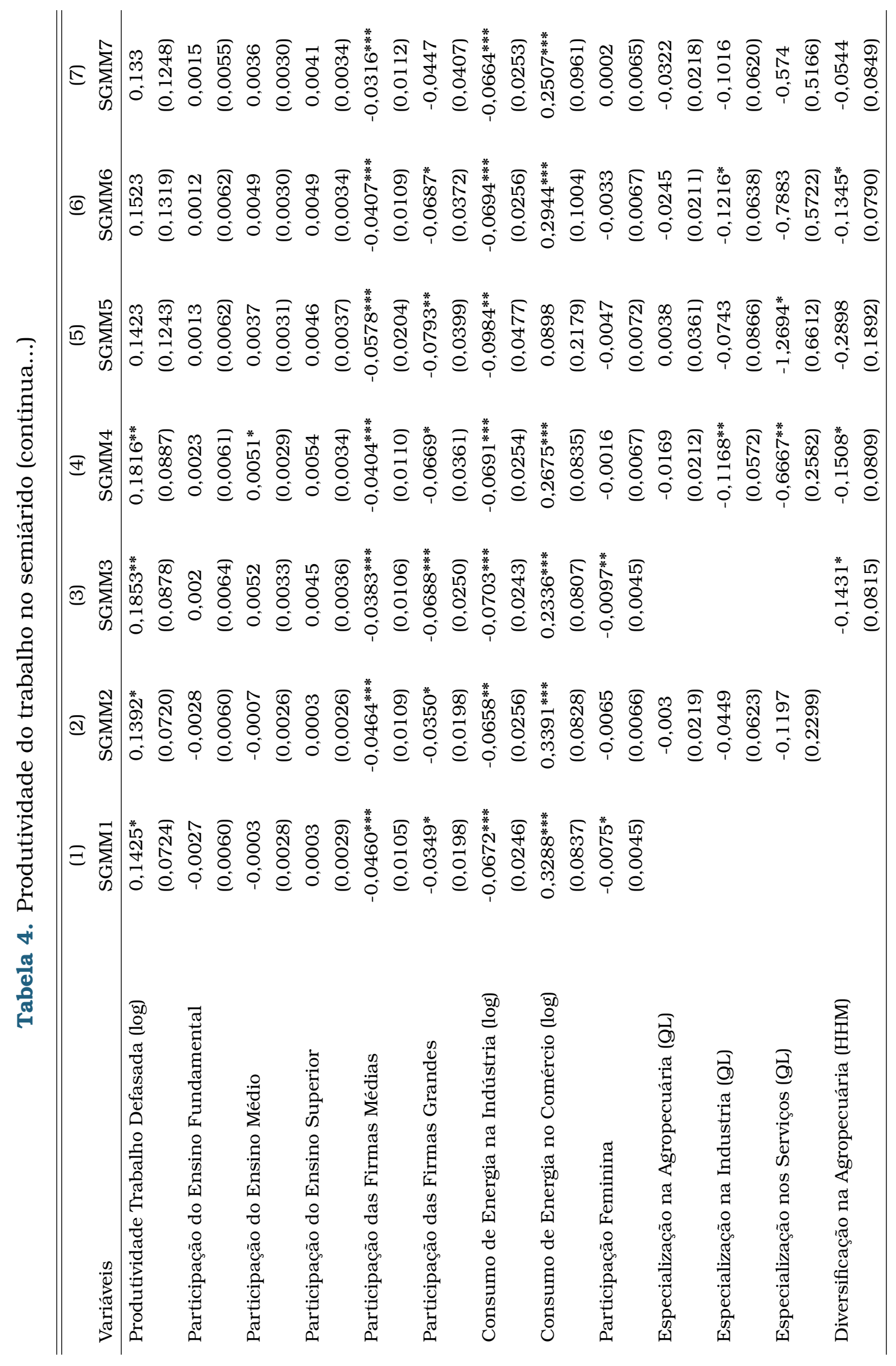




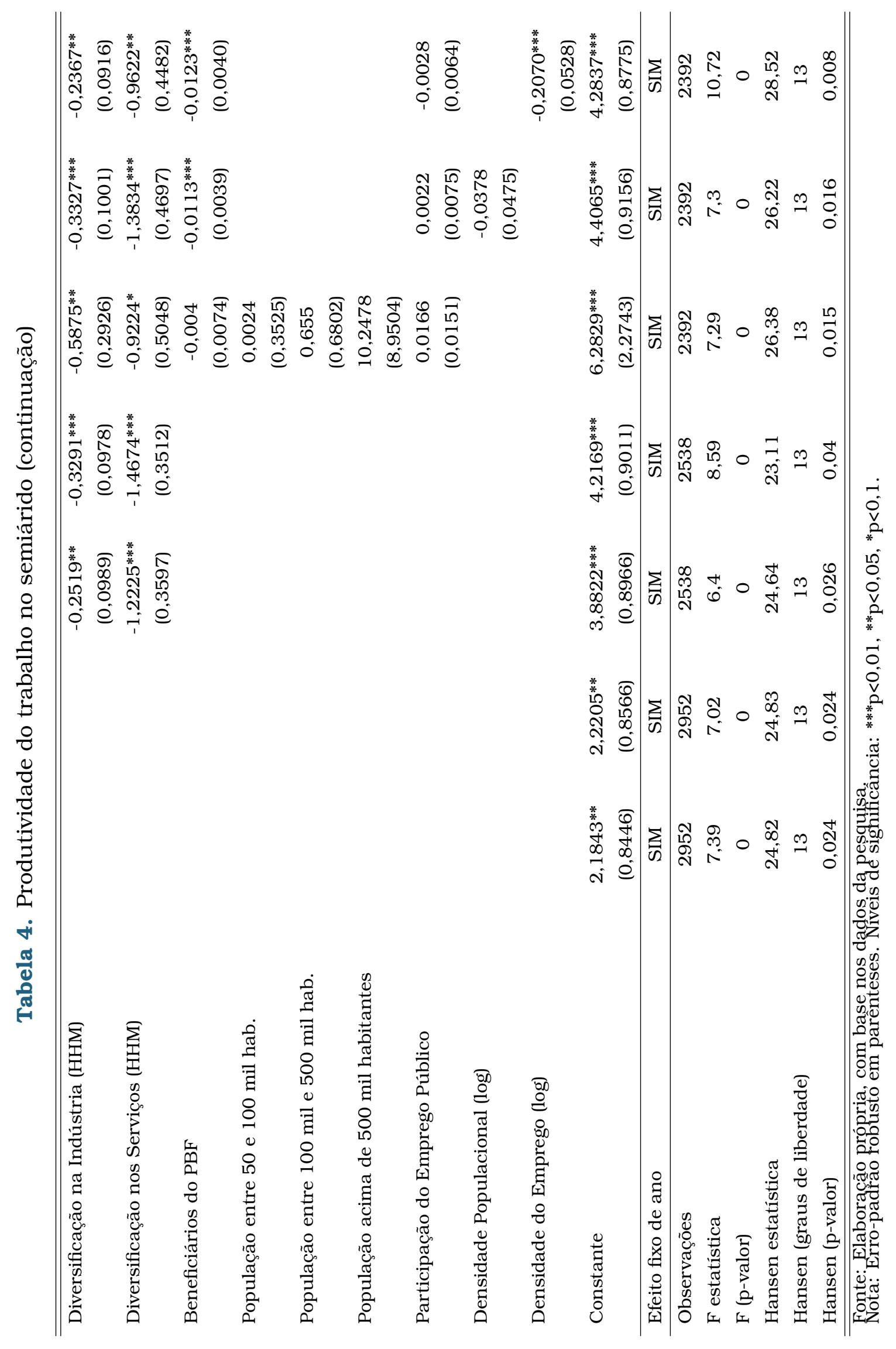


A parcela de empregos no setor público apresentou efeito positivo e significativo sobre a produtividade do trabalho para os municípios do Grupo 1 (SGMM6). Esse é um resultado importante, pois evidencia que o emprego público apresenta relevância para a geração de renda desses municípios. Ao mesmo tempo, é importante considerar a relação entre o emprego público e o privado e como isso pode explicar os resultados da produtividade do trabalho. De acordo com os estudos de Faggio e Overman (2014) e Loyo et al. (2018), para a Inglaterra e o Brasil, respectivamente, a geração de emprego no setor público pode ter um efeito multiplicador ou eliminador de empregos no setor privado. Sendo assim, o efeito positivo do setor público também pode estar associado a uma redução no emprego privado. De modo geral, os resultados proporcionam evidências que são compatíveis com outros estudos sobre o tema, em que o comportamento de variáveis econômicas estruturais é fortemente dependente da sua trajetória passada recente e por isso levaria um tempo maior para mudarem significativamente.

As variáveis de interesse utilizadas para captar efeitos de economias de aglomeração (as faixas populacionais) no SGMM5 não impactaram como esperado na produtividade. Esse resultado contradiz a teoria convencional de economias de aglomeração. De acordo com Glaeser e Resseger (2010), a produtividade do trabalhador estaria relacionada à população das áreas metropolitanas, pois essas cidades teriam maiores níveis de qualificação dos trabalhadores. Assim, é notável que os municípios baianos possuem características que evidenciam um comportamento diverso do convencional. Esse resultado é corroborado pela variável densidade do emprego (SGMM7), com efeito negativo e significativo nos coeficientes para ambos os grupos. Como ressaltado, por Ciccone e Hall (1996), a densidade do emprego pode gerar efeitos diversos sobre a produtividade do trabalho, aqui ela se mostrou negativamente correlacionada com a produtividade em ambos os grupos. Uma possível explicação para esse resultado está no fato de a maioria dos municípios baianos possuírem um baixo número de empregos formais e pouca presença de indústrias.

Perobelli e Haddad (2006) constataram que as aglomerações não se mostraram relevantes para o crescimento econômico da região Nordeste devido à sua fraca estrutura produtiva. Como ressaltado, por Hirschman (1958), uma estrutura de produção forte é um dos fatores responsáveis pelo desenvolvimento de uma economia. Por isso, é necessário que sejam desenvolvidas políticas públicas que estimulem a produção dos setores, algo essencial para a região adquirir dinamismo local próprio.

Os resultados para os municípios do Grupo 2 apresentam diferenças marcantes se comparados aos demais, de acordo com a Tabela 4. Na regressão em que se controla apenas pelo conjunto inicial de variáveis socioeconômicas - SGMM1 -, uma mudança na produtividade passada está associada com um crescimento de $0,14 \%$ na produtividade corrente. Quando são adicionadas mais variáveis de controle, esse percentual se reduz e o parâmetro da produtividade defasada perde significância estatística. Os parâmetros que indicam concentração ou especialização (QL) e diversificação (HHM) setoriais apresentam efeitos diferentes do esperado (SGMM4). O efeito negativo apre- 
sentado pelos indicadores aponta que nem a especialização nem a diversificação setorial contribuem para a produtividade do trabalho, o que pode ser explicado pela estrutura produtiva pouco desenvolvida.

Variáveis de tamanho de firmas não apresentaram contribuições relevantes para o aumento da produtividade do trabalho em nenhum dos grupos. As parcelas de firmas médias e grandes apresentaram efeitos negativos sobre a produtividade. Uma possível explicação para a ausência de efeito no caso das grandes empresas é o fato de a maioria dos municípios baianos não possuírem muitas, ou até nenhuma, firmas de grande porte. Portanto, dada a baixa proporção de firmas grandes no estado da Bahia, particularmente em seu Semiárido, é esperado não haver evidências de tais efeitos positivos sobre a produtividade do trabalho. No que se refere às variáveis educacionais, apenas a parcela de trabalhadores com ensino médio mostrou relação positiva com a produtividade do trabalho, no SGMM4 para o Grupo 2. Ainda assim, os efeitos da variável apontam para externalidades positivas do investimento em educação na região do Semiárido, embora esses efeitos possam ser heterogêneos.

Sobre os efeitos associados à parcela de beneficiários do Programa Bolsa Família (PBF), foi observada uma relação negativa e significativa da variável com a produtividade do trabalho para ambos os grupos. Uma possivel justificativa para isso é a condição de pobreza na maioria dos munícipios baianos, especialmente os que compõem o Semiárido. Nesse sentido, o PBF não contribui para a elevação da produtividade do trabalho, sendo apenas uma forma de garantir uma renda mínima para as famílias. Adicionalmente, a maior parte dos beneficiários possui baixa ou nenhuma qualificação, fazendo com que essas pessoas participem menos do mercado de trabalho formal ou não tenham acesso.

Por fim, observou-se que poucos indicadores parecem ter contribuído para explicar o comportamento observado da produtividade do trabalho ${ }^{6}$. No caso específico do estado da Bahia, há questões relevantes que podem dificultar o aumento da produtividade, uma vez que a maior parte dos municípios está localizada na região do Semiárido do estado. Essa região é caracterizada por elevados índices de pobreza e por um baixo nível de desenvolvimento socioeconômico e isso certamente afeta os indicadores de produtividade. Ademais, questões históricas relacionadas à maneira como o desenvolvimento econômico ocorreu no estado e a perda de participação e influência da Bahia no processo de crescimento econômico brasileiro também podem explicar os resultados encontrados, além das questões relacionadas à alta informalidade do trabalho, fator que afeta tanto os municípios do interior quanto as regiões metropolitanas do estado.

\footnotetext{
${ }^{6}$ Foi realizado um exercício de robustez buscando testar a existência de deseconomias de aglomeração (externalidades negativas) decorrentes do aumento da concentração produtiva, populacional e do emprego. Para tanto, incluíram-se as versões quadráticas do $\mathrm{QL}$, do HHM e das densidades populacional e do emprego. Em geral, os resultados não indicaram a presença de deseconomias de aglomeração. Além disso, foram encontrados efeitos positivos e estatisticamente significantes para as versões quadráticas do QL dos serviços e do HHM da indústria, apenas em duas especificações, e para a densidade do emprego no Semiárido (cerca de 0,04\%).
} 


\section{Considerações finais}

A Bahia é um estado grande e diverso, marcado por características socioeconômicas espacialmente desiguais. Nesse sentido, buscou-se analisar os efeitos das economias de aglomeração sobre a produtividade do trabalho na Bahia no período recente, tendo como base um conjunto de modelos estimados em um painel dinâmico, através do método GMM System. Ao estimar o conjunto de modelos para o Grupo 1, incluindo todo o conjunto de variáveis (SGMM7), encontramos que a produtividade do trabalho passada gerou um aumento de $0,49 \%$ na produtividade do trabalho no ano seguinte.

O percentual de firmas médias e grandes apresentou efeitos negativos sobre a produtividade do trabalho da Bahia. Isso pode sugerir que há ineficiência na cadeia produtiva baiana, assim como ausência de tecnologias para o desenvolvimento de inovações e ampliação de relações comerciais. No entanto, a parcela de firmas grandes é ainda muito baixa, o que pode limitar a sua capacidade de ampliação da produtividade média. A proxy para a infraestrutura e estoque de capital local usada para o comércio apresentou efeito positivo para ambos os grupos, contribuindo para um aumento na ordem de 0,09\% na produtividade do trabalho dos municípios do Grupo 1 e 0,25\% para os municípios do Grupo 2, considerando o modelo com todas as variáveis.

A densidade do emprego apresentou efeito negativo para ambos os grupos. Esse resultado pode refletir a dinâmica dos grandes centros da Bahia, com alta parcela da população empregada em ocupações informais. A maioria dos indicadores de concentração de aglomerados especializados e diversificação produtiva apresentaram sinal negativo. Essa relação negativa dos coeficientes com a produtividade deve ser vista com preocupação pelos formuladores de política de desenvolvimento produtivo local, pois, como foi discutido anteriormente, a especialização produtiva pode contribuir positivamente para o aumento da produtividade. Já a diversificação pode ter efeitos diversos a depender do estágio de desenvolvimento econômico regional e urbano.

A variável da parcela de beneficiários do Programa Bolsa Família apresentou efeito negativo para ambos os grupos, indicando que a maior dependência dos programas de transferência de renda pode limitar a ampliação da produtividade do trabalho. Assim, para aumentar a produtividade do trabalho nos municípios baianos são necessárias políticas específicas de desenvolvimento produtivo e regional, voltadas para a amenização das desigualdades educacionais e de acesso ao mercado de trabalho formal, tais como o investimento em capital físico e humano, a melhoria da qualidade institucional, dentre outros.

Os efeitos das economias de aglomerações que se tentou captar através das faixas por tamanho populacional apresentaram efeitos negativos para a faixa de 50 a 100 mil habitantes no Grupo 1. Em outras palavras, baixos índices de aglomeração populacional parecem afetar negativamente a produtividade do trabalho, para o caso dos municípios que estão fora da região do Semiárido. No entanto, de forma geral, os efeitos das aglomerações nos grandes centros urbanos da Bahia parecem estar limitados 
a questões de ordem estrutural. Portanto, não foram encontrados efeitos relevantes de economias de aglomeração que corroborassem o crescimento da produtividade do trabalho. A economia baiana é altamente dependente de choques exógenos de crescimento, especialmente no que se refere à demanda agregada.

Há alterações substanciais na análise feita entre os grupos de municípios que compõem o Semiárido. De forma geral, é possivel observar que a relação da produtividade do trabalho com as demais variáveis diminui e perde significância estatística a partir do SGMM5 no Grupo 2. Portanto, os municípios baianos do Semiárido são mais marcados por uma fraca estrutura produtiva e possuem desigualdades socioeconômicas acentuadas que refletem de forma mais proeminente sobre a produtividade do trabalho. A produtividade do trabalho tem sido um foco de importantes pesquisas em países e regiões em desenvolvimento. O crescimento sustentado da produtividade é diretamente ligado à capacidade de inovação dos setores, ao investimento em capital físico e, evidentemente, em capital humano. Esses elementos, alinhados a uma boa infraestrutura e qualidade institucional, são capazes de desenvolver as regiões e propiciar melhorias no bem-estar de toda a sociedade. No entanto, os efeitos dos indicadores da produtividade do trabalho variam ao longo do tempo, de acordo com a complexidade que a economia desenvolve. Isso acentua ainda mais a importância de investimentos públicos e privados em fatores como a educação, a redução das desigualdades socioeconômicas, o estímulo à competitividade das firmas e as melhorias no ambiente institucional.

É importante ressaltar que, embora a proposta de abordagem metodológica adotada não permita levar em consideração a possivel existência de dependência espacial no modelo, e esse não tenha sido o foco do trabalho, a existência de spillovers espaciais pode gerar um viés nas estimativas encontradas. Nesse sentido, uma possivel extensão do presente estudo avaliaria a existência de dependência espacial no modelo considerado. Por fim, é importante salientar que futuros trabalhos sobre o tema são essenciais para contribuir para o debate e sugerir políticas efetivas para o desenvolvimento produtivo do estado da Bahia. A ausência de dados em nível municipal com periodicidade anual limita a realização de estudos mais aprofundados, a exemplo de informações sobre a informalidade e a qualidade da infraestrutura e das instituições, o que se constitui uma fragilidade para esta pesquisa. Porém, ressalta-se que a análise apresentada contribui para a formação de uma agenda política e para debates que objetivem se aprofundar nos aspectos relativos ao mercado de trabalho, à diminuição das desigualdades regionais, à produção, ao crescimento sustentado e ao desenvolvimento do estado.

\section{Referências}

Abdel-Rahman, H. M. (1988). Product differentiation, monopolistic competition and city size. Regional Science and Urban Economics, 18(1):69-86. 
Anderle, R. V., Magalhães, A. M., e de Moraes Rocha, R. (2018). Crescimento da produtividade dos municípios nordestinos e a questão espacial: a hipótese dos fatores espaciais comuns. Revista Brasileira de Estudos Regionais e Urbanos, 12(1):90-109.

Arellano, M. e Bond, S. (1991). Some tests of specification for panel data: Monte Carlo evidence and an application to employment equations. The Review of Economic Studies, 58(2):277-297.

Arellano, M. e Bover, O. (1995). Another look at the instrumental variable estimation of error-components models. Journal of Econometrics, 68(1):29-51.

Battisti, M., Del Gatto, M., e Parmeter, C. F. (2018). Labor productivity growth: disentangling technology and capital accumulation. Journal of Economic Growth, 23(1):111-143.

Blundell, R. e Bond, S. (1998). Initial conditions and moment restrictions in dynamic panel data models. Journal of Econometrics, 87(1):115-143.

Blundell, R. e Bond, S. (2000). Gmm estimation with persistent panel data: an application to production functions. Econometric Reviews, 19(3):321-340.

Bronzini, R. e Piselli, P. (2009). Determinants of long-run regional productivity with geographical spillovers: the role of $\mathrm{RD}$, human capital and public infrastructure. Regional Science and Urban Economics, 39(2):187-199.

Bustelo, M., Flabbi, L., Piras, C., e Tejada, M. (2019). Female labor force participation, labor market dynamic, and growth.

Cameron, A. C. e Trivedi, P. K. (2005). Microeconometrics: methods and applications. Cambridge University Press.

Cavalcante, L. R. e De Negri, F. (2014). Evolução recente dos indicadores de produtividade no Brasil. Produtividade no Brasil: Desempenho e Determinantes.

Choudhry, M. T. (2009). Determinants of labor productivity: An empirical investigation of productivity divergence. Citeseer.

Ciccone, A. e Hall, R. E. (1996). Productivity and the density of economic activity. American Economic Review, 87(2):54-70.

Combes, P.-P., Duranton, G., Gobillon, L., Puga, D., e Roux, S. (2012). The productivity advantages of large cities: Distinguishing agglomeration from firm selection. Econometrica, 80(6):2543-2594.

Conti, G. (2005). Training, productivity and wages in Italy. Labour Economics, 12(4):557-576.

Correa Junior, C. B., Trevisan, L. N., e Mello, C. H. P. d. (2019). Impactos do Programa Bolsa Família no mercado de trabalho dos municípios brasileiros. Revista de Administração Pública, 53(5):838-858. 
de Almeida, E. T., de Moraes Rocha, R., e Gomes, S. M. F. P. O. (2017). Economias de aglomeração e o crescimento das indústrias intensivas em tecnologia: evidências para o Nordeste no período 2002-2014. Revista Brasileira de Estudos Regionais e Urbanos, 11(4):467-494.

Faggio, G. e Overman, H. (2014). The effect of public sector employment on local labour markets. Journal of Urban Economics, 79:91-107.

Freguglia, R. d. S., Kern, A. P., e Vieira, M. T. (2018). Impacto do Programa Bolsa Família na oferta de trabalho dos beneficiários. Anais do $46^{\circ}$ Encontro Nacional de Economia da ANPEC.

Freitas Merelles, A. E. e Santos, J. P. C. (2018). A dinâmica do setor de serviços na bahia e seus impactos sobre os municípios e o mercado de trabalho entre os anos de 2006 e 2015. Bahia Análise e Dados, 27(2):87-103.

Fugita, M. (1988). A monopolistic competition model of spatial agglomeration: Differentiated product approach. Regional Science and Urban Economics, 18:87-124.

Gambetti, L. e Pistoresi, B. (2004). Policy matters: The long run effects of aggregate demand and mark-up shocks on the Italian unemployment rate. Empirical Economics, 29:209-226.

Garofalo, A., Rycx, F., Vinci, C. P., Aldieri, L., Cincera, M., Garofalo, A., e Vinci, C. P. (2008). Micro evidence of the effects of R\&D on labour productivity for large international R\&D firms. International Journal of Manpower, 8(1):34-49.

Glaeser, E. L. e Resseger, M. G. (2010). The complementarity between cities and skills. Journal of Regional Science, 50:221-244.

Henderson, J. (2003). Marshall's scale economies. Journal of Urban Economics, 53:128.

Henderson, J. V. (1999). Marshall's scale economies, nebr. National Bureau of Economic Research), Working Paper.

Hirschman, A. O. (1958). The strategy of economic development, Yale Univ. Press New Haven, 3(1):1-28.

Hoffmann, R. (2007). Transferências de Renda e Redução da Desigualde no Brasil e em Cinco Regiões, entre 1997 e 2005.

Holtz-Eakin, D., Newey, W., e Rosen, H. S. (1988). Estimating vector autoregressions with panel data. Econometrica: Journal of the Econometric Society, 3(1):1371-1395.

IBGE (2017). Produto Interno Bruto dos Municípios. Instituto Brasileiro de Geografia e Estatística. Disponivel em: https://www.ibge.gov.br. Acesso em: 01 julho 2020. 
IBGE (2018). Cidades e estados. Instituto Brasileiro de Geografia e Estatística. Disponivel em: https://www.ibge.gov.br/cidades-e-estados/ba.html. Acesso em: 01 julho 2020.

Jacobs, J. (1970). The economy of cities. Vintage.

Klein, A. e Crafts, N. (2020). Agglomeration externalities and productivity growth: US cities, 1880-1930. The Economic History Review, 73(1):209-232.

Komatsu, B. K. e Menezes-Filho, N. A. (2015). Salário mínimo e desigualdade salarial: um estudo com densidades contrafactuais nas regiões metropolitanas brasileiras. Instituto de Pesquisa Econômica Aplicada (Ipea).

Krüger, J. J. (2008). Productivity and structural change: a review of the literature. Journal of Economic Surveys, 22(2):330-363.

Lokshin, B., Belderbos, R., e Carree, M. (2008). The productivity effects of internal and external R\&D: Evidence from a dynamic panel data model. Oxford bulletin of Economics and Statistics, 70(3):399-413.

Loyo, A. d. O. L., Resende-Filho, M. d. A., e Mendes, V. L. (2018). Impacto de mudanças no emprego no setor público sobre o mercado de trabalho local: evidências para as mesorregiões brasileiras de 2003 a 2010. Estudos Econômicos, 48(1):77-106.

Manso, J. R. P. (2005). Relações de causalidade entre consumo de energia, evolução da produtividade e crescimento do produto: uma abordagem recorrendo à metodologia var. Documento de Trabalho. Departamento de Gestão e Economia Universidade da Beira Interior-Portugal.

Marchante, A. J. e Ortega, B. (2012). Human capital and labor productivity: A study for the hotel industry. Cornell Hospitality Quarterly, 53(1):20-30.

Marshall, A. (1890). Principles of Economics, London: Mac-Millan. Originally Published.

Messa, A. (2015). Determinantes da produtividade na indústria brasileira. Instituto de Pesquisa Econômica Aplicada (Ipea).

Moura, T. T. S., Prates, T. M., e Cabral, A. M. R. (2020). Crescimento econômico nos municípios de alagoas entre 2000 e 2015: uma aplicação de painel dinâmico. Instituto de Pesquisa Econômica Aplicada (Ipea).

Nakamura, R. (1985). Agglomeration economies in urban manufacturing industries: a case of Japanese cities. Journal of Urban Economics, 17(1):108-124.

Perobelli, F. S. e Haddad, E. A. (2006). Padrões de comércio interestadual no Brasil, 1985 e 1997. Revista de Economia Contemporânea, 10(1):61-88.

Raiher, A. P. (2020). Economies of agglomeration and their relation with industrial productivity in Brazilian municipalities. Papers in Regional Science, 99(3):725-747. 
Raiher, A. P. e Candido, M. J. (2018). Aglomeraçõeses produtivas da região sul do Brasil e sua relação com a produtividade industrial. Revista Brasileira de Estudos Regionais e Urbanos, 12(1):17-34.

Rice, P., Venables, A. J., e Patacchini, E. (2006). Spatial determinants of productivity: Analysis for the regions of Great Britain. Regional science and urban economics, 36(6):727-752.

Sacchet, S. e Calixtre, A. B. (2011). Características da formalização do mercado de trabalho brasileiro entre 2001 e 2009. Instituto de Pesquisa Econômica Aplicada (Ipea).

Schettini, D. e Azzoni, C. R. (2015). Determinantes regionais da produtividade industrial: O papel da infraestrutura. Instituto de Pesquisa Econômica Aplicada (Ipea).

SEI (2015). Economia e social. Superintendência de estudos Econômicos e Sociais da Bahia. Disponivel em: http://www.sei.ba.gov.br. Acesso em: 24 junho 2020.

SEI (2020). Contas regionais na Bahia (2002-2016). Superintendência de estudos Econômicos e Sociais da Bahia. Disponivel em: http://www.sei.ba.gov.br. Acesso em: 10 janeiro 2021.

Sousa Filho, J. F. d., Santos, G. F. d., e Ribeiro, L. C. S. (2020). Structural changes in the Brazilian economy 1990-2015. Economic Systems Research, Página 1-21.

Spilimbergo, A. e Srinivasan, K. (2019). Brazil: Boom, bust, and the road to recovery. International Monetary Fund.

Squeff, G. C. e De Negri, F. (2013). Produtividade do trabalho e rigidez estrutural no Brasil nos anos 2000. Instituto de Pesquisa Econômica Aplicada (Ipea).

Squeff, G. C. e De Negri, F. (2014). Produtividade do trabalho e mudança estrutural no Brasil nos anos 2000. Produtividade no Brasil: Desempenho e Determinantes.

SUDENE (2007). Delimitação do semiárido. Superintendência de Desenvolvimento do Nordeste. Disponivel em: http://www.sudene.gov.br/delimitacao-do-semiarido. Acesso em: 09 julho 2020.

Suzigan, W., Furtado, J., Garcia, R., e Sampaio, S. E. (2003). Coeficientes de Gini locacionais-GL: aplicação à indústria de calçados do Estado de São Paulo. Nova Economia, 13(2).

Van Beveren, I. (2012). Total factor productivity estimation: A practical review. Journal of Economic Surveys, 26(1):98-128.

@Ev Este artigo está licenciado com uma CC BY 4.0 license. 